\title{
SYSTEM IDENTIFICATION VIA FAST RELAXED VECTOR FITTING FOR THE STRUCTURAL HEALTH MONITORING OF MASONRY BRIDGES
}

\author{
Marco Civera $^{a}$, Giulia Calamai ${ }^{\mathrm{b}}$, Luca Zanotti Fragonara ${ }^{\mathrm{c}}$ \\ ${ }^{a}$ Department of Mechanical and Aerospace Engineering (DIMEAS), Politecnico di Torino, Corso Duca \\ degli Abruzzi 24, Turin, 10129, Turin, Italia. \\ ${ }^{b}$ Department of Structural, Building and Geotechnical Engineering (DISEG), Politecnico di Torino, Corso \\ Duca degli Abruzzi 24, Turin, 10129, Turin, Italia. \\ ${ }^{c}$ Centre for Autonomous and Cyber-Physical Systems, Cranfield University, Cranfield, Bedford \\ $M K 43 O A L$, Cranfield, UK
}

\begin{abstract}
The increasingly request for the maintenance of the architectural heritage has led in the last decades to the extensive use of System Identification (SI) techniques for Structural Health Monitoring (SHM) purposes. These proved to be useful tools for assessing the state of conservation of the built environment and its behaviour in operating conditions. In particular, historical masonry structures and infrastructures present several compelling difficulties. Masonry is non-linear and its mechanical properties are uncertain due to the presence of local irregularities and its internal texture. Moreover, centuries-old buildings are severely affected by deterioration, eventual restoration interventions, and exposure to weather conditions. In this work, the Fast Relaxed Vector Fitting (FRVF) approach is proposed as a rapid, efficient, and reliable instrument for the vibration-based SI of such structures. The method is preliminarily validated on simple numerical examples and a multi-damaged cantilevered box beam, then tested on a true 1:2 scaled model of a masonry two-span arch bridge. The results match well the estimations from other well-established SI techniques, such as the Eigensystem Realization Algorithm (ERA), and can be utilised for damage assessment (with all the standard
\end{abstract}


advantages and limitations of modal-based outlier detection). Stabilisation diagrams and frequency-damping plots are also proposed for FRVF.

\section{Keywords:}

Masonry bridges; bridge monitoring; architectural heritage; structural health monitoring; system identification; experimental modal analysis; non-destructive testing; stabilization diagram.

\section{Introduction}

Any structure or infrastructure is subject to external and internal phenomena which diminish their mechanical resistance and safety reliability over time. Therefore, the probability of structural failure or collapse naturally increases along time due to ageing and natural material degradation. This can be due to both regular use and consumption or to extraordinary events such as floods, earthquakes, blasts or any natural or man-made large-impact event. The issue is particularly relevant for historical and cultural heritage. The cost of the potential loss of unique, centennial, and non-replaceable works of art can be very high. Thus, Structural Health Monitoring (SHM) and System Identification (SI) are necessary to safely operate these facilities and to guarantee the seismic resilience of heritage structures [1]; if properly utilised, a monitoring system can provide useful insight and support the decision-making process concerning the safety, maintenance and economy of structures. However, the monitoring of historical and architectural sites is complex and demand a deep level of knowledge and analysis of both the structural and non-structural (e.g. ornamental) components [2].

Masonry arch bridges are the main focus of this research. They are commonly found all around the European landscape, especially throughout the French, Italian, and English countryside. These, like other historical masonry structures, were built since hundreds of years ago, without the modern precautions such as strict geometric tolerances; moreover, technical 
details regarding their construction have been lost and the understanding of the construction practices at the time of building is not at all an easy task and requires large efforts of historical research. Even more, many hidden local defects are present since their construction or have developed unnoticed. The construction material itself is relatively challenging if compared to more homogeneous materials such as steel: masonry has some (limited) tensile strength, even if it is generally omitted in design for safety [3]. Bricks and mortar are well-known to behave and interact nonlinearly and accordingly to complex models (for instance, Reference [4] analysed in detail the evolutionary phenomenon of mortar de-bonding); splitting or surface spalling may happen due to stress concentration over time, and loss of bricks cohesion, while generally unlikely, is not impossible. The interested audience may refer to Reference [5] for a deeper discussion about the structural performances of masonry bridges in the context of Structural Bridge Engineering.

There are simply too many case studies of structural monitoring for large historical masonry buildings to be enlisted here completely; a throughout discussion can be found in Reference [6]. It is possible to recall the dynamic monitoring system developed for the Vicoforte Sanctuary [7]. In the specific case of historic and masonry bridges, some relevant contributions to the topic can be found in the works of Azzara et al.[8], Conde et al. [9,10], De Falco et al. [11], Gönen \& Soyöz [12], Han et al. [13], Manos et al. [14,15], and many others well-known case studies [16-18] to name a few. Some recent advances in SHM for masonry buildings include a spectral entropy approach [19], multivariate statistical analysis [20], and many more. In this work, an imposed settlement was utilised to cause damage growth, similar to the problem addressed by [21] for masonry buttressed arches. This simulates a progressive erosion, which is known to produce a sensible decrease in the bridge natural frequencies due to the decreasing stiffness [22]. 
For all these purposes, experimental and operational modal analysis (EMA and OMA, respectively) have both been extensively applied (for instance, see Reference [23]). Indeed, modal analysis is, by far, the most common approach to monitor and assess any mechanical or civil structure. The appearance and developing of structural changes, such as the occurrence of damage, can be determined and tracked by the changes in the dynamic behaviour of the structure in terms of frequencies and ways of vibrating. In this sense, input-output strategies for EMA are highly regarded for their robustness and accuracy. By scaling the vibrational response over the applied input, the identified parameters as they depend exclusively on the intrinsic characteristics of the structure (masses, stiffness, damping, boundary conditions, etc.) and not on the external loads.

This research promotes an implementation for SHM purposed of the Fast Relaxed Vector Fitting (FRVF) technique, stemmed from Electrical Engineering [24,25]. The method has been adapted to mechanical vibrations by exploiting the classic mechanical-electrical analogies. Its potential for the vibration-based identification of damage is preliminarily tested on two numerical case studies and a simple experimental one, a cantilevered aluminium box beam with two saw cuts (one straight and one slanted). The FRVF approach is then validated on a 1:2 scale replica of a masonry arch bridge, realised and tested in the laboratories of the Department of Structural, Geotechnical and Building Engineering at the Politecnico di Torino, and subject to simulated scour by a dedicated settlement application system. The aim is to exploit the changes in the lower natural frequencies to track the developing damage, which is a well-known and established technique in Vibration-Based SHM [26]. A more detailed discussion about the vibrational behaviour of historical masonry bridges can be found in Reference [27]. 
The rest of this paper is organised as follow. The theory of FRVF is described in Section 2. Some reminders about system identification, pole stability, and similar concepts are provided for completeness. Section 3 reports a numerical example for a discrete 3 degrees-offreedom (DoFs) system and an analytical example for a continuous cantilever beam. Section 4 deals with the first experimental case study. Section 5 presents and analyses the masonry arch bridge, and the Conclusions end this paper.

\section{System Identification with Poles and Residues.}

The FRVF technique discussed here is an input-output system identification algorithm for experimental modal analysis, which can be used with any number of input and/or output channels (i.e., it can be adapted as a SISO, SIMO, or MIMO approach [28]) and to any type of input source. Importantly, its first definition (as well as its application here) is formulated in the frequency domain, but a variant in the time-domain can also be found in the scientific literature $[29,30]$. However, time-domain methods have the disadvantage that they can only estimate modes inside the frequency range of analysis and take no account of the residual effects of modes that lie outside the range. For this reason, frequency-domain techniques are generally more commonly encountered in practical applications [31].

The FRVF works by approximating the Transfer Function (TF) between the recorded output and the known input. This can be done for any form of the input (force, displacement, velocity, or acceleration) and the output; for simplicity, here the formulation between the input force $F$ and the output displacement $Y$ will be used; this is known as the system's Receptance Frequency Response Function, or FRF. To better define it, it is needed to rapidly recall some basics definitions. A pole of a mechanical system with a single degree of freedom can be defined in the Laplace domain, i.e. in the complex s-plane, as 


$$
s_{1,2}=\sigma \pm i \omega_{d}
$$

where, being a complex pair, $s_{2}=s_{1}^{*}$. The receptance FRF can be approximated by a partial fraction form defined as

$$
H(s)=\frac{Y(s)}{F(s)} \cong \frac{A}{\left(s-s_{1}\right)}+\frac{A^{*}}{\left(s-s_{2}\right)}
$$

Where $A=-\frac{1}{i 2 m \omega_{d}}$ and its complex conjugate $A^{*}$ are the residues of $H(s)$. It is very easy to translate this TF, here expressed in terms of poles and residues, in the frequency domain. Consider that the real part of $s_{1,2}$ can be written as

$$
\sigma=-\zeta \omega_{n}
$$

while its imaginary component derives from the damped natural angular frequency of the corresponding mode $\omega_{d}$, i.e.

$$
\omega_{d}=\omega_{n} \sqrt{1-\zeta^{2}}
$$

where $\zeta$ is the damping ratio and $\omega_{n}=\sqrt[2]{k / m}$ is the natural pulsation of the $n$-th mode. Thus, by evaluating $H(s)$ for the particular case where $\sigma=0$ (i.e. for a purely imaginary argument), the Laplace Transform is reduced to a Fourier Transform and it is possible to prove that [31]

$$
\begin{gathered}
H(\omega)=\left.H(s)\right|_{s=i \omega}=\left.\left[\frac{A}{\left(s-s_{1}\right)}+\frac{A^{*}}{\left(s-s_{1}^{*}\right)}\right]\right|_{s=i \omega}= \\
\frac{A}{\left(i \omega-s_{1}\right)}+\frac{A^{*}}{\left(i \omega-s_{1}^{*}\right)}=\frac{A}{i\left(\omega-\omega_{d}\right)+\zeta \omega_{n}}+\frac{A^{*}}{i\left(\omega+\omega_{d}\right)+\zeta \omega_{n}}=\frac{1}{-m \omega^{2}+i c \omega+k}
\end{gathered}
$$

It is then possible to define the physical properties of the system - i.e. its mass $m$, stiffness $k$, and viscous damping $c=2 m \zeta \omega_{n}$ - from its vibrational response; by tracking them along time for a constant mass, frequency shifts can be linked to changes in stiffness and therefore to developing damage.

The right end side of Eq. (2) can be expanded to multi-DoFs systems in form of a sum of partial fractions as 


$$
f(s)=\sum_{n=1}^{N} \frac{A_{n}}{s-s_{n}}+H_{\infty}
$$

Where $H_{\infty}$ governs the behaviour at high frequencies and may be split into two components, the real quantity $d$ and the product se [24]. It is then needed to consider an unknown function $\sigma(\mathrm{s})$ defined as:

$$
\sigma(s) \approx \sum_{n=1}^{N} \frac{\tilde{A}_{n}}{s-\tilde{s}_{n}}+1
$$

By multiplying $f(s)$ and $\sigma(s)$, the following problem can be stated:

$$
\left[\begin{array}{c}
\sigma(s) f(s) \\
\sigma(s)
\end{array}\right] \approx\left[\begin{array}{c}
\sum_{n=1}^{N} \frac{A_{n}}{s-\tilde{s}_{n}}+d+s e \\
\sum_{n=1}^{N} \frac{\tilde{A}_{n}}{s-\tilde{s}_{n}}+1
\end{array}\right]
$$

The poles of $\sigma(s) f(s)$ are the same rational approximation of $\sigma(s)$. By forcing $\sigma(s)$ to approach unity at very high frequencies (that is to say, for $H_{\infty}=1$ ), the ambiguity is removed from the solution for $\sigma(s)$ [24]. This leads to

$$
\sigma(s) f(s) \approx\left(\sum_{n=1}^{N} \frac{\tilde{A}_{n}}{s-\tilde{s}_{n}}+1\right) f(s) \approx \sum_{n=1}^{N} \frac{A_{n}}{s-\tilde{s}_{n}}+d+s e
$$

where

$$
(\sigma f)_{f i t}(s) \approx(\sigma)_{f i t}(s) f(s)
$$

After some mathematical steps, it is possible to demonstrate that:

$$
d+\sum_{n} \frac{A_{n}}{s-s_{n}} \approx H(s)\left(d^{\prime}+\sum_{n} \frac{A_{n}^{\prime}}{s-s_{n}}\right)
$$

Which describes the relationship between the transfer function, $H(s)$, and the fitted residues, $\left[A_{n}, A_{n}^{\prime}\right]$, poles $\left[s_{n}, s_{n}^{\prime}\right]$, and constant terms $\left[d, d^{\prime}\right]$. The right-hand side of Eq. (11) approaches $H(s)$ 
as the solution converges; this can be done iteratively by solving it as a least-square (LS) problem. This completes the basic definition of VF. In comparison to this formulation, a Fast Relaxed VF implementation (FRVF; [32]) has been applied. Specifically, this includes a relaxed non-triviality constraint added in the pole identification procedure, that is to say, considering a real-valued free variable $\hat{d}$,

$$
\sigma(s)=\sum_{n=1}^{N} \frac{\tilde{A}_{n}}{s-s_{n}}+\hat{d}
$$

With the only constrain that the sum of the real parts of $\sigma(s)$ must be non-null, to avoid a trivial solution. This simple variation has a twofold advantage since it makes the choice of the initial poles less critical (as they are freer to rearrange over larger distances of the s-plane, which is useful in the first iterations of the procedure) and improve overall the convergence of the problem. The linear problem is then solved by the QR decomposition approach as suggested in [33], decomposing the LS matrix of interest into the product of a matrix $Q$ of orthonormal basis and an upper triangular matrix of coefficients $R$. This step significantly reduces the computational effort and the memory storage required [25].

\subsection{Comparison with Similar Approaches.}

One of the most common algorithms for the identification of the modal parameter is, at the current time, the Rational Fraction Polynomial (RFP; see e.g. [34], Subsection 4.3.1). However, this method is notoriously affected by the several limitations typical of the polynomial approximations of functions. For instance, the nonlinear fitting problem is generally non-convex, with multiple local minima. On the other hand, the VF algorithm operates a (weighted) linearised minimisation [35]. The FRVF is also especially efficient computationally thanks to the QR decomposition [36], as it will be highlighted in the next Sections. 
Another common approach is the Eigensystem Realisation Algorithm (ERA; [37]). This algorithm for the identification of the modal parameters is commonly used by researchers and practitioners, yet its limits and drawbacks are well-known. For example, for a nonstationary input, its stability and accuracy are greatly affected, with up to $50 \%$ error increase in damping estimation [38].

\section{Numerical and Analytical Case Studies.}

A 3-storey shear-type frame structure and a continuous cantilever beam have been simulated for synthetic data. The intended purpose is to explicate the potentiality of the FRVF approach for modal analysis before seeing it applied for the detection of damage-induced frequency shifts. For the first case (Figure 1.a), the structure and assumption on the frame mechanical behaviour allows considering the masses as concentrated on every single floor, thus making it essentially a 3 DoFs system, with mass and stiffness matrices

$$
[M]=\left[\begin{array}{ccc}
m_{1} & 0 & 0 \\
0 & m_{2} & 0 \\
0 & 0 & m_{3}
\end{array}\right],[K]=\left[\begin{array}{ccc}
k_{1}+k_{2} & -k_{2} & 0 \\
-k_{2} & k_{2}+k_{3} & -k_{3} \\
0 & -k_{3} & k_{3}
\end{array}\right]
$$

With $m_{i}=1 \mathrm{~kg}$ and $k_{i}=5000 \mathrm{~N} / \mathrm{m}$ set for any $i$-th floor. Rayleigh's proportional damping model has been implemented with a default value of $3 \%$. To obtain the structure response on any floor, a simulated unitary impulse $(1 \mathrm{~N})$ was imposed at the first DoF. The receptance FRFs were calculated by simply dividing the Fourier Transform (FT) of the displacement output at any storey over the FT of the external force for each frequency step. The result is a 3-by-1 complex array of transfer functions (the absolute values of which are reported in Figure 1.b). Only the $0-25 \mathrm{~Hz}$ frequency range was used for fitting, as all modes fall in between these two bounds.

Results for the model of order six (which is theoretically supposed to capture all the three modes of the simulated structure) are represented in Figure 2. The input data and their rational approximations are reported, respectively, as solid blue and dashed red lines . The deviation between 
the magnitude of $(\sigma)_{f i t}(s) f(s)$ and $(\sigma f)_{f i t}(s)$ is illustrated in light green and was found to be nowhere larger than 1e-8. The estimated poles and residues of the state space system are reported in Table 1. The derived modal parameters - eigenfrequencies, eigenshapes, and modal damping ratios - are reported in Table 2 (the mode shapes are normalised over the maximum displacement). These results compare well with the ones extracted using the well-known ERA algorithm. Figure 3.a shows graphically the linear regression of the natural frequencies.

It can be noticed that, as expected, all the poles have a negative real part and are therefore stables (Figure 3.b). Their trend is also coherent with an underdamped response after perturbation; indeed, it is well-known that a complex conjugate pair $\sigma \pm i \omega$ in the left-half of the plane generates a decaying sinusoid $Y e^{-\sigma t} \sin \left(\omega_{d} t+\varphi\right)$, with amplitude $Y$, phase $\varphi$, and decay rate $\sigma=\zeta \omega_{n}$. Finally, the obtained mode shapes are portrayed in Figure 4.a The goodness of fit for mode shapes was computed through the Modal Assurance Criterion (MAC; [39]) and can be visualised in the right side of Figure 4.b Again, the vectors of modal displacements resulting from the FRVF procedure resemble the analytically derived ground truth with $>99.9 \%$ accuracy. In terms of computational time, a non-optimised script of the FRVF algorithm (implemented in MatLab R2018b and tested on an Intel ${ }^{\circledR}$ Core ${ }^{\mathrm{TM}}$ i7-7700HQ CPU with $2.80 \mathrm{GHz}$ base frequency) ran in $0.0398 \mathrm{~s}$ (enforcing stable poles, without skipping both pole and residue identification, and considering 5 iterations), while the ERA code elapsed $0.8828 \mathrm{~s}$. This proves the superior computational efficiency of the Fast variant of the RVF approach on an ideal, noise-free dataset. 


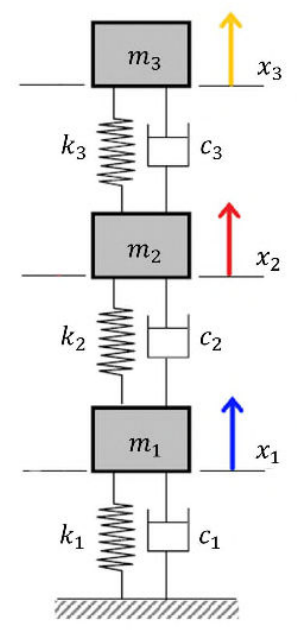

(a)

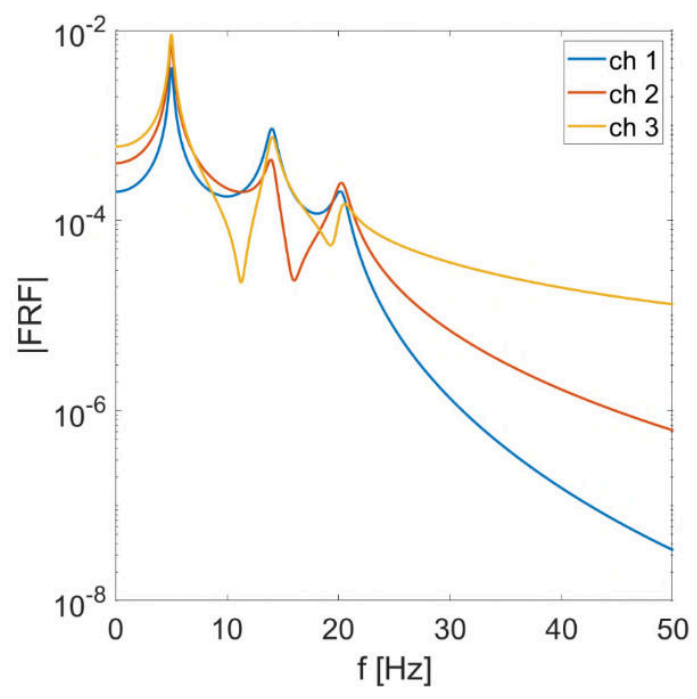

(b)

Figure 1. (a) Three-stories frame schematic design. (b) The receptance FRFs of the numerical 3DoFs example, response channels 1-3 (is in semilogarithmic scale).

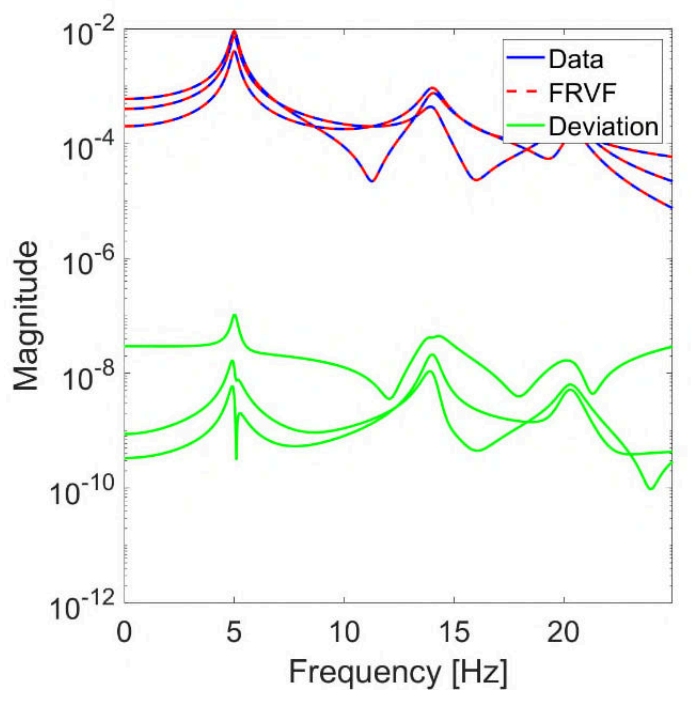

(a)

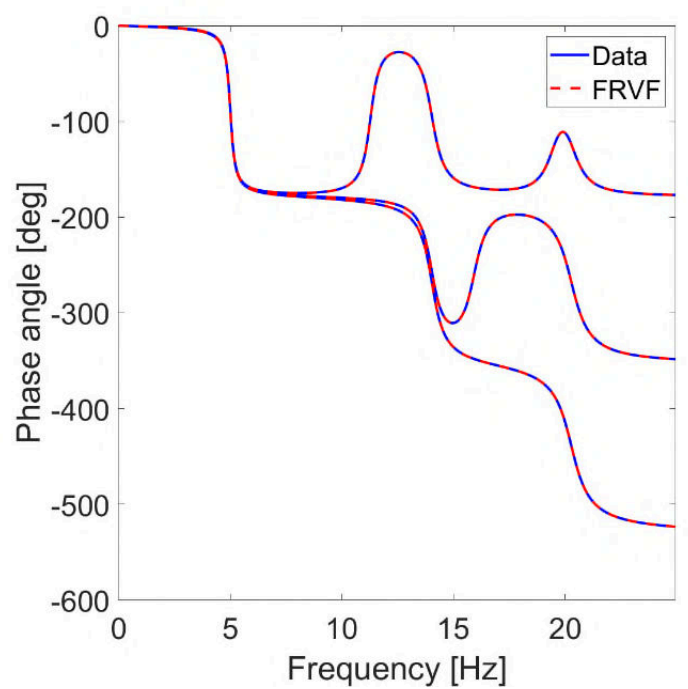

(b)

Figure 2. Fitting over the SIMO system with three output channels (one per story). (a): Plot of the absolute value of gain. (b): phase angle. 


\begin{tabular}{|c|c|c|c|c|}
\hline Mode & Pole & $\begin{array}{c}\text { Residue (1st } \\
\text { number }\end{array}$ & $\begin{array}{c}\text { Residue (2nd } \\
\text { output channel) }\end{array}$ & Residue (3rd \\
output channel)
\end{tabular}

Table 1. Poles and residues of the 3DoF frame numerical example.

\begin{tabular}{|c|c|c|c|c|c|}
\hline $\begin{array}{c}\text { Mode } \\
\text { number }\end{array}$ & $\begin{array}{c}\text { Frequency } \\
{[\mathrm{Hz}]}\end{array}$ & $\begin{array}{c}\text { Damping } \\
{[-]}\end{array}$ & \multicolumn{3}{|c|}{$\begin{array}{c}\text { Mode shape } \\
{[-]}\end{array}$} \\
\hline & \multicolumn{5}{|c|}{ FRVF } \\
\hline $\mathbf{1}$ & 5.01 & 0.030 & 0.4450 & 0.8019 & 1 \\
\hline 2 & 14.04 & 0.030 & -1 & -0.4450 & 0.8020 \\
\hline \multirow[t]{2}{*}{3} & 20.28 & 0.030 & 0.8019 & -1 & 0.4450 \\
\hline & \multicolumn{5}{|c|}{ ERA } \\
\hline 1 & 5.01 & 0.030 & 0.4450 & 0.8019 & 1 \\
\hline 2 & 14.03 & 0.030 & -1 & -0.4450 & 0.8019 \\
\hline \multirow[t]{2}{*}{3} & 20.28 & 0.030 & 0.8019 & -1 & 0.4450 \\
\hline & \multicolumn{5}{|c|}{ Exact Value (Analytical Solution) } \\
\hline 1 & 5.01 & 0.030 & 0.4450 & 0.8019 & 1 \\
\hline 2 & 14.03 & 0.030 & -1 & -0.4450 & 0.8019 \\
\hline
\end{tabular}




\begin{tabular}{|l|l|l|l|l|l|}
\hline $\mathbf{3}$ & 20.27 & 0.030 & 0.8019 & -1 & 0.4450 \\
\hline
\end{tabular}

Table 2. Modal parameters of the 3DoF frame numerical example.

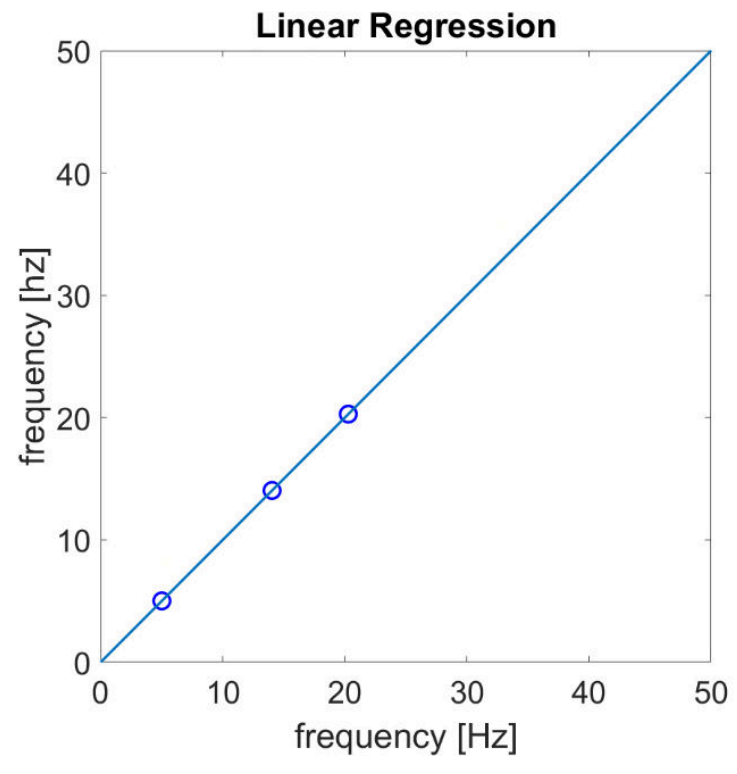

(a)

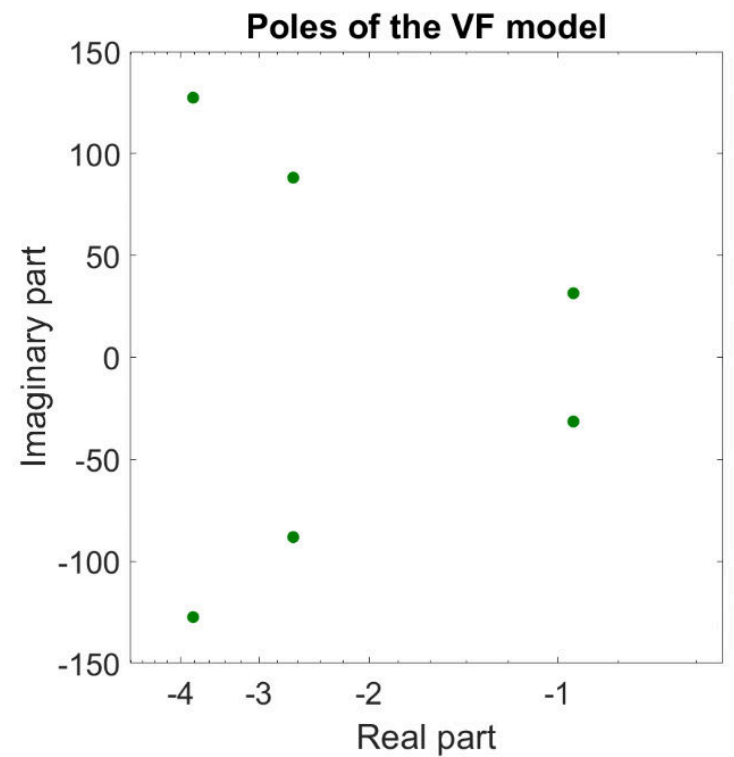

(b)

Figure 3. (a): Linear regression of the natural frequencies. (b): Trend of identified poles.

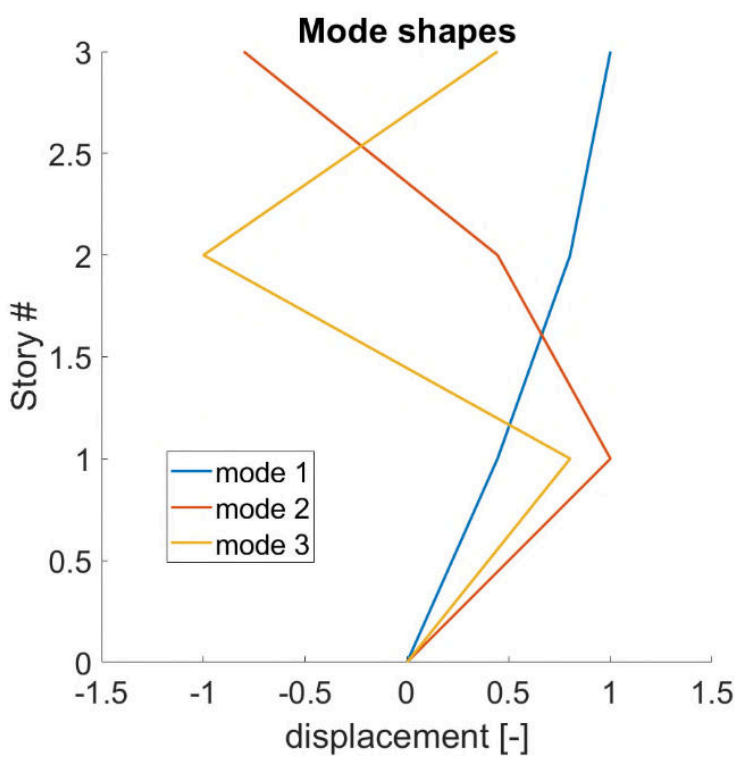

(a)

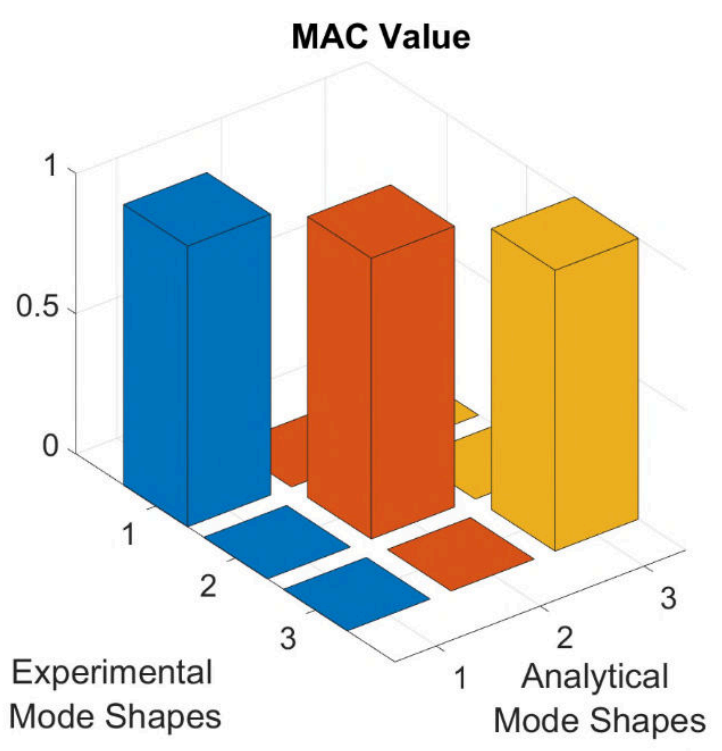

(b) 
Figure 4. (a): Mode shapes of the 3DoF frame numerical example. (b): corresponding MAC values (dark blue: first mode; green: second mode; yellow: third mode).

The second synthetic case study involves the analytical definition of a continuous cantilevered beam, sketched in Figure 5 and defined as

$$
H_{\alpha \beta}(\omega)=\sum_{k=1}^{M} \frac{\psi_{k}\left(x_{\alpha}\right) \psi_{k}\left(x_{\beta}\right)}{m_{k}\left(\omega_{k}^{2}-\omega^{2}+i 2 \zeta_{k} \omega_{k} \omega\right)}(14)
$$

Where $\alpha$ is the input degree of freedom, $\beta$ the output degree of freedom, and $\psi_{k}, m_{k}, \zeta_{k}$ and $\omega_{k}$ are, respectively, the $k$-th mode shape, modal mass, modal damping ratio and resonance frequency (expressed in radians). In Figure 5, the 10 dots indicate the respective 10 channels. The green dot at channel \#7 indicates its coincidence with the single node of the first mode shape. Channels \#4 and \#8 are coincident with the two nodes of the second mode shape, and channels \#2, $\# 5$, and \#9 are located at the nodes of the third one. The assumed clamped-free beam has geometrical dimensions 20 x 20 x $800 \mathrm{~mm}$, Young's modulus $210 \mathrm{GPa}$, and density equal to $7900 \mathrm{~kg} / \mathrm{m}^{3}$. Since the analytical definition can span (theoretically) for infinite DoFs, order 18 was arbitrarily set for the FRVF algorithm. This ultimately results in identifying the first nine modes. For the sake of this second investigation, all channels were utilised one at a time for simulating the application of the input, while the remaining ones were left for recording the output. This resulted in a square matrix of 6-by-6 FRFs, which is the best application for the FRVF approach as it returns the most reliable characterisation (even if, in practical terms, it is much easier to use one or a few input application points and many more output acquisition channels). For simplicity and easiness of visualisations the transfer functions $H_{3,10}, H_{4,10}, H_{6,10}, H_{7,10}, H_{9,10}$, and $H_{10,10}$ are reported separately in Figure 6 . The common set of poles is shown in Figure 7. As for the 3-DoFs system, the error was everywhere negligible an less than $5 \cdot 10^{-4} \mathrm{~Hz}$ frequency-wise and $0.1 \%$ on the mode shapes. For comparison, 
the poles obtained from the Eigensystem Realization Algorithm are shown in Figure 7; the two methods returned an almost perfect superposition. The FRVF script elapsed 0.0229 seconds per input-output pair (with the same settings as for the previous numerical case), while ERA took 0.5109 s to complete the same task.

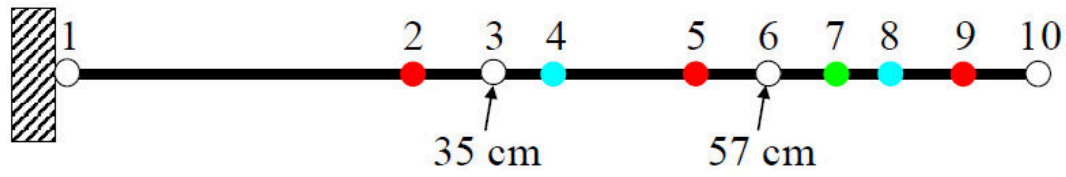

Figure 5. Graphical scheme of the continuous cantilevered beam.
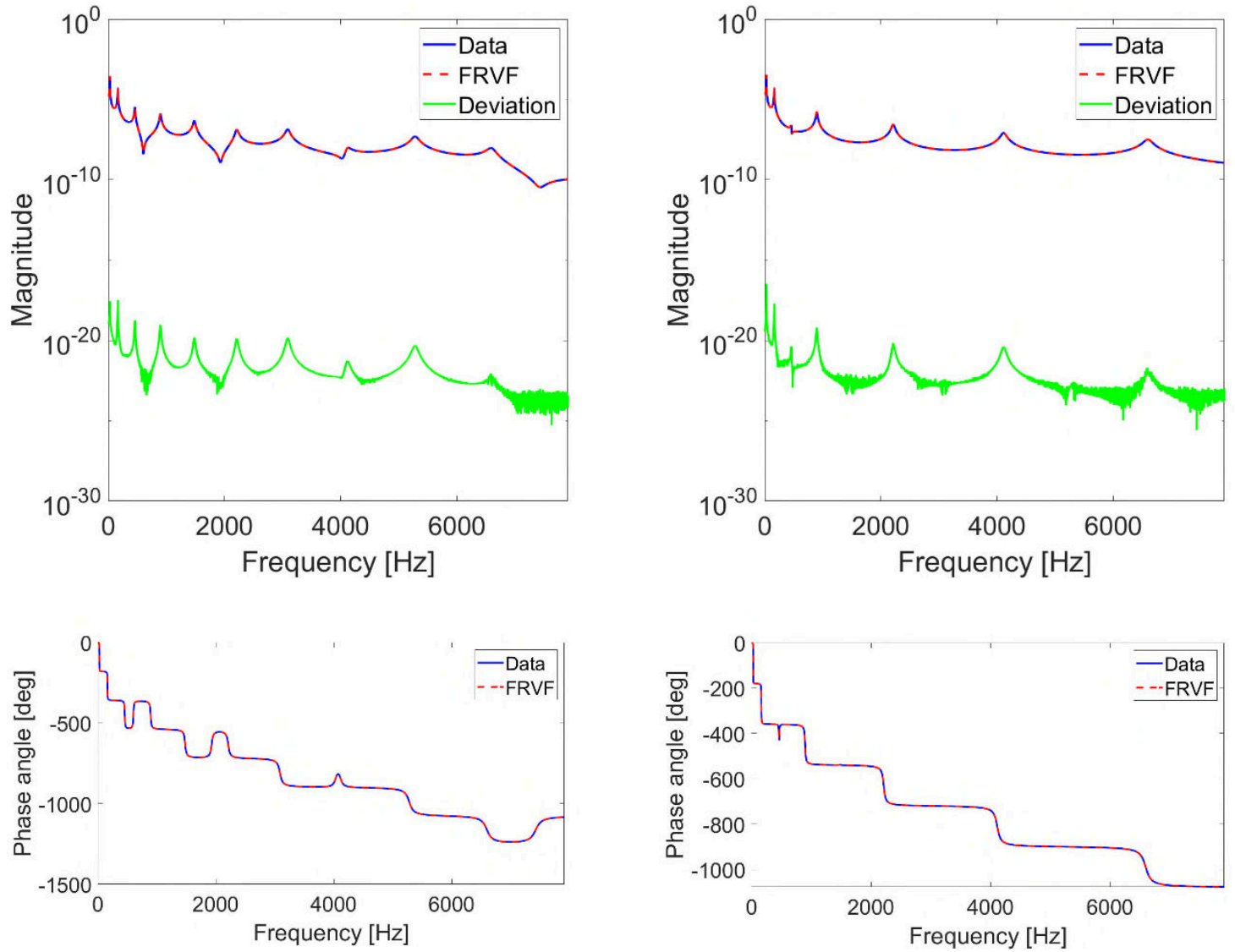
$H_{3,10}$
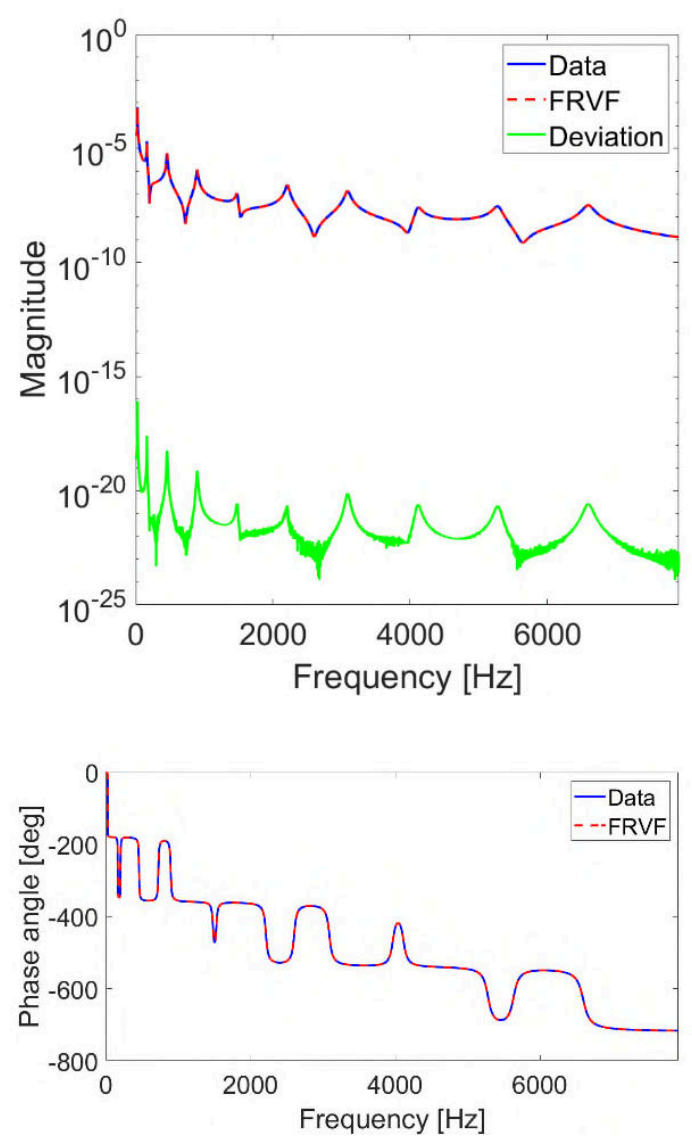

$H_{6,10}$
$H_{4,10}$
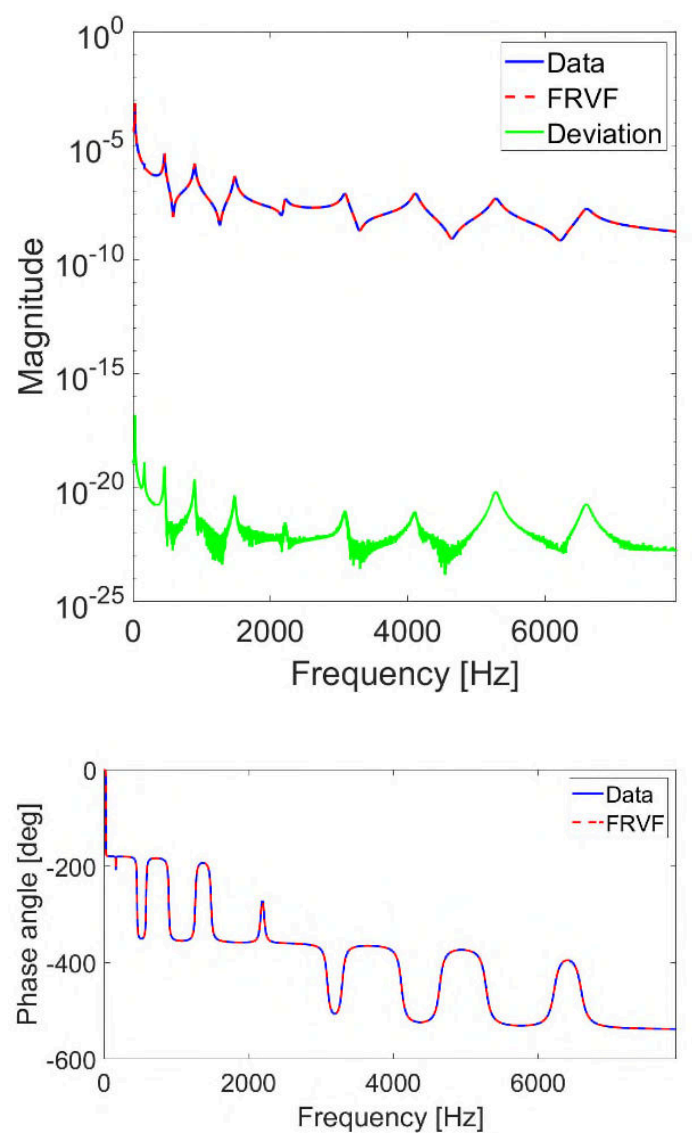

$H_{7,10}$ 

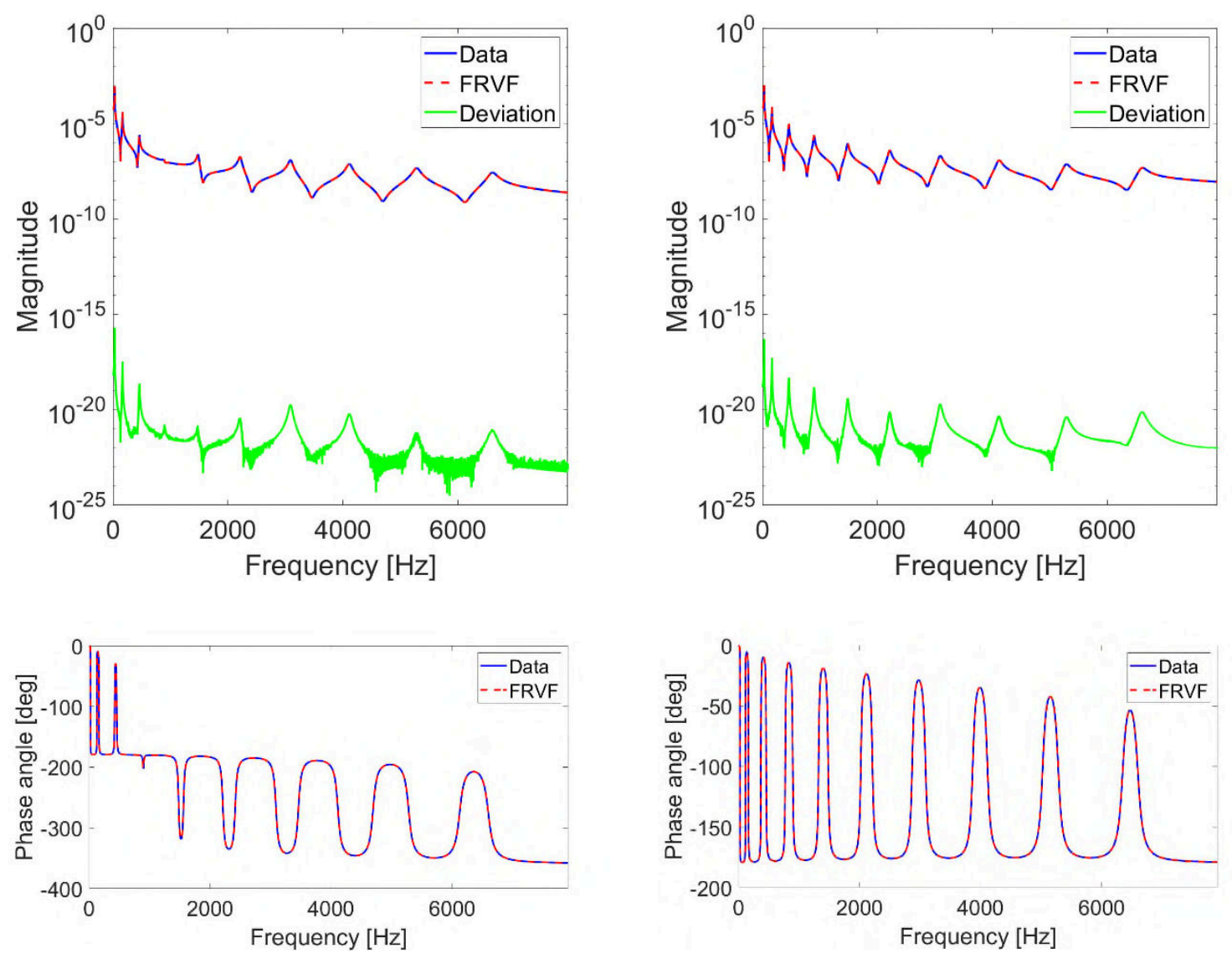

$$
H_{9,10}
$$

$$
H_{10,10}
$$

Figure 6. Fitting over the MIMO system with nine input and output channels (results displayed separately). For every subplot, top: the plot of the absolute value of gain; bottom: the phase angle.

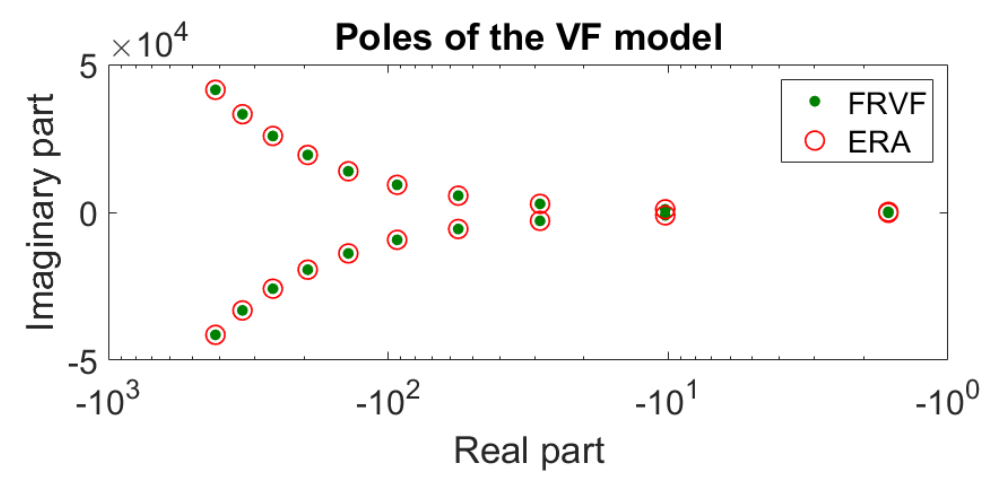

Figure 7. The trend of identified poles for the continuous cantilevered beam synthetic example. Green dots: FRVF. Red circles: ERA. 


\section{Preliminary Experimental Case Study: The Aluminium Box Beam}

An aluminium cantilevered box beam (Figure 8) has been used for the first validation of the advantages of the FRVF technique for SHM purposes. The aim for this introductive example was to follow the decrease of the first natural frequency for an increasing level of damage in a single input, single output experimental setup. Matching the results reported in [40] was set as the target for successful damage detection.

The test was realised at Cranfield University to investigate the effects of increasing damage considering multiple slots and slanted crack angle; the damages were emulated employing straight saw cuts [40]. The box beam has Young's modulus of $69 \mathrm{GPa}$, mass per unit length of $0.322 \mathrm{~kg} / \mathrm{m}$, a free length of $716 \mathrm{~mm}$, and a hollow square cross-section with sides 25 $\mathrm{mm}$-long and $2 \mathrm{~mm}$-thick. The first notch is located at $x_{1}=205 \mathrm{~mm}$ from the clamped section and is a perfectly vertical saw cut, while the second one is positioned at $x_{2}=319 \mathrm{~mm}$ and has a 5:1 inclination respect to the vertical (i.e. a slant angle of $11.3^{\circ}$ ). The dynamic tests consisted of $11-\mu s-$ long triangular impulses of $5 \mathrm{~g}$ peak acceleration, applied by a modal shaker attached to the fixed end. The natural frequencies as estimated by the FRVF algorithm were compared with the values obtained by running the ERA algorithm on the same output signals. In both cases, the values reported in Table 3 for the levels of increasing damage severity) correspond to the identifications averaged over three consecutive inputs (the standard deviation is reported in brackets). The algorithm performs overall well, correctly following the shift of the $1^{\text {st }}$ and $2^{\text {nd }}$ natural frequencies due to the increasing damage in $x_{2}$. The average elapsed time was of $0.5182 \mathrm{~s}$ for the ERA and $0.0257 \mathrm{~s}$ for the FRVF. 


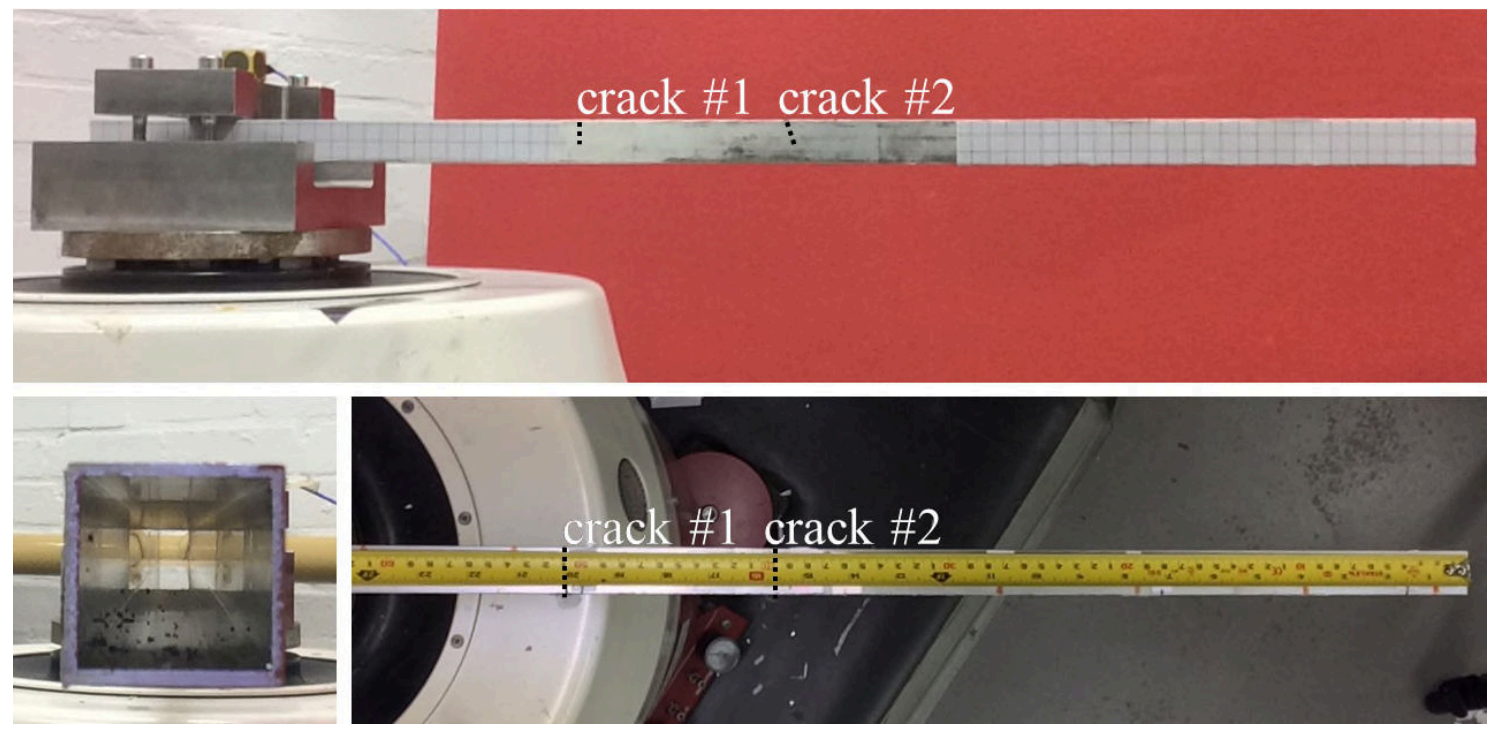

Figure 8 . The multi-damaged cantilever box beam.

\begin{tabular}{|c|c|c|c|c|c|c|}
\hline \multirow[t]{2}{*}{\begin{tabular}{|c|} 
Damage \\
severity case
\end{tabular}} & \multicolumn{2}{|c|}{ damage depth $(*)$} & $\begin{array}{c}1^{\text {st }} \text { natural } \\
\text { frequency - } \\
\text { ERA }\end{array}$ & $\begin{array}{c}1^{\text {st }} \text { natural } \\
\text { frequency - } \\
\text { FRVF }\end{array}$ & $\begin{array}{c}2^{\text {nd }} \text { natural } \\
\text { frequency - } \\
\text { ERA }\end{array}$ & $\begin{array}{c}2^{\text {nd }} \text { natural } \\
\text { frequency - } \\
\text { FRVF }\end{array}$ \\
\hline & $d_{1}[\mathrm{~mm}]$ & $d_{2}[\mathrm{~mm}]$ & {$[\mathrm{Hz}]$} & {$[\mathrm{Hz}]$} & {$[\mathrm{Hz}]$} & {$[\mathrm{Hz}]$} \\
\hline no damage & - & - & $46.19(0.05)$ & $46.28(0.16)$ & $288.52(0.14)$ & $287.81(0.14)$ \\
\hline$\# 1$ & 15 & no damage & $36.40(0.11)$ & $36.34(0.27)$ & $285.98(0.18)$ & $286.02(0.19)$ \\
\hline$\# 2$ & 15 & 5 & $36.23(0.18)$ & $36.20(0.17)$ & $280.00(0.19)$ & $279.52(0.27)$ \\
\hline$\# \mathbf{3}$ & 15 & 10 & $34.51(0.25)$ & $35.49(0.28)$ & $264.62(0.23)$ & $265.29(0.29)$ \\
\hline$\# 4$ & 15 & 15 & $33.37(0.03)$ & $33.81(0.04)$ & $234.75(0.20)$ & $234.45(0.19)$ \\
\hline
\end{tabular}

(*) intended as the vertical component of length; corresponding to damage extension for

$$
l_{1}=d_{1} \text { but not for } l_{2}=d_{2} / \cos (\beta)>d_{2} \text {. }
$$

Table 3. Damage levels for the box beam experimental case study. 


\section{Main Experimental Case Study: The Masonry Arch Bridge}

\subsection{Test Setup}

The main case study recreates the typical characteristic of an Italian masonry twin-arch bridge. The two arches have a radius of $2.00 \mathrm{~m}$ and an angular opening of $30^{\circ}$. The two spans are both $2.00 \mathrm{~m}$-long between the supports and the thickness of the arch equals to $0.20 \mathrm{~m}$. These and the other main geometric parameters are reported in Table 4. The model was created with clay bricks scaled to $130 \times 65 \times 30 \mathrm{~mm}$ to respect the adopted modelling scale law and installed on two reinforced concrete slabs, fixed in turn to the laboratory floor. Low compressive strength elements were chosen and mortar with poor mechanical properties was used to bound them to recreate the typical materials of historical buildings [41]. A photo portrait of the bridge can be seen in Figure 9.a. Backfill material, composed by sand, gravel, and debris of different size, was used to load and stabilise the arch barrels. This was further topped with a $10 \mathrm{~cm}$-thick layer of concrete to obtain a levelled plane.

The purpose of the whole experimental test was to reproduce the effects of scour at the foundation of the central pier, which is considered as if placed inside the streambed and thus subjected to the erosion of the soil underneath its foundation. This event was reproduced utilising a dedicated settlement application system, inserted at the hypothetical middle-height of the mid-span masonry pier and able to replicate the displacements and rotations along the two axes corresponding to the transverse and longitudinal directions of the bridge (Figure 9.b). These displacements and rotations were calibrated over the results of several hydraulic flume tests executed on a scaled-down model of the bridge central pier, which will be described in the following Subsection. The Young's modulus, Poisson coefficient, and density of the building materials were estimated through both $S$ and $P$ wave velocities, as well as destructive tests. The mortar was characterised via compression and three-point bending tests accordingly to the prescriptions of the European standard code EN 
998-2:2003, returning (averaged over three prismatic samples) a mean bending strength of $1.092 \mathrm{~N} / \mathrm{mm}^{2}$ and a mean compressive strength $3.975 \mathrm{~N} / \mathrm{mm}^{2}$.

The masonry samples underwent axial and diagonal compression tests (both on six cubic samples), plus shear and four points bending tests (Figure 10). The shear tests were performed with two different pre-compression loads $(0.1 . \mathrm{kN}$ and $0.5 \mathrm{kN})$, both on three samples of masonry triplets. Three arch segments were used for the four points bending tests. All the tests were performed, in the same order, following the guidelines prescribed in UNI EN 1052-1, EN 1052-3:2002, and ASTM E 518-02 (in this last case, except for the geometric form of the specimens, as it was tested directly on three replicas of the arch; all details are available in [41-43]).

The axial compression tests returned a mean value of Young's modulus equal to 1451 $\mathrm{N} / \mathrm{mm}^{2}$, with a standard deviation of $472 \mathrm{~N} / \mathrm{mm}^{2}$. The diagonal compression tests and the shear tests highlighted the nonlinear behaviour of the bricks and mortar joints, as well as a great level of uncertainty, which is not uncommon for these materials due to the presence of local irregularities and the effects of the internal texture. The shear tests with $0.1 \mathrm{kN}$ pre-compression load returned the mean value $\mu=0.794 \mathrm{~N} / \mathrm{mm}^{2}$ with standard deviation $\sigma=0.301 \mathrm{~N} / \mathrm{mm}^{2}$. The $0.5 \mathrm{kN}$ precompression load returned $\mu=1.013 \mathrm{~N} / \mathrm{mm}^{2}$ and $\sigma=0.188 \mathrm{~N} / \mathrm{mm}^{2}$. Finally, $\mu=0.430 \mathrm{~N} / \mathrm{mm}^{2}$ and $\sigma=0.125 \mathrm{~N} / \mathrm{mm}^{2}$ were estimated from the diagonal compression tests. In all cases, the ultimate shear strength was calculated as the stress which caused the complete opening of the cracks in the mortar joints. The modulus of rupture of the arch (which can be considered as its overall shear resistance [43]) was estimated via the four points bending tests as circa $0.220 \mathrm{~N} / \mathrm{mm}^{2}$. Other inherent material properties are reported in Table 5. Furthermore, polystyrene was added around and beneath the central pier foundation, to simulate the riverine sediments (the polystyrene was chosen since it has a stiffness comparable to the riverbed material). Two layers were set: a $25 \mathrm{~mm}$-thick polystyrene base, located in between the bottom of the pier and the upper face of the settlement application 
system steel plate, and a $100 \mathrm{~mm}$-thick ring layer on the top of the base, surrounding the pier foundation (see Figure 9.b). The ring layer was then progressively removed, to emulate the erosion on the foundation sides as evaluated during the hydraulic tests. The removal was done by hand, cutting off with a knife the upper portion of the ring layer, homogeneously around the four sides. The thin base layer beneath the central pier, on the other hand, was left untouched during all the tests. Further technical devices were adopted to reduce the uncertainty related to the boundary conditions, to avoid the rocking of the abutment during the model construction, and to better replicate in situ effects; all the operations carried out are furthermore elaborated in much more detail in Reference [43].

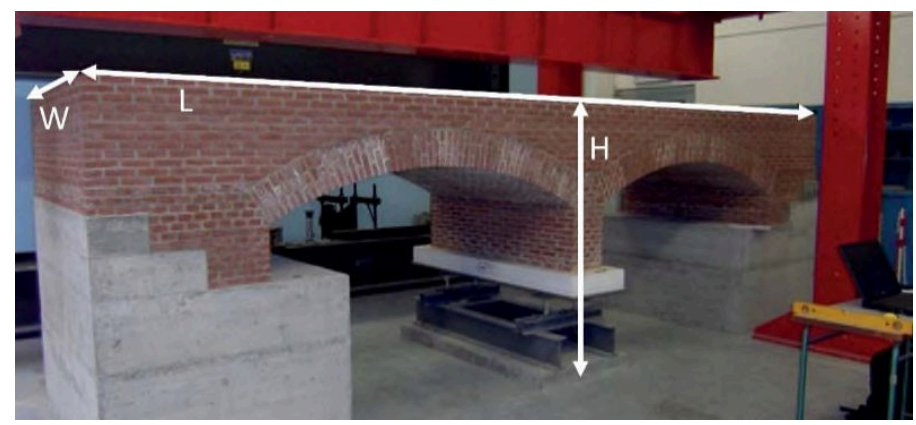

(a)

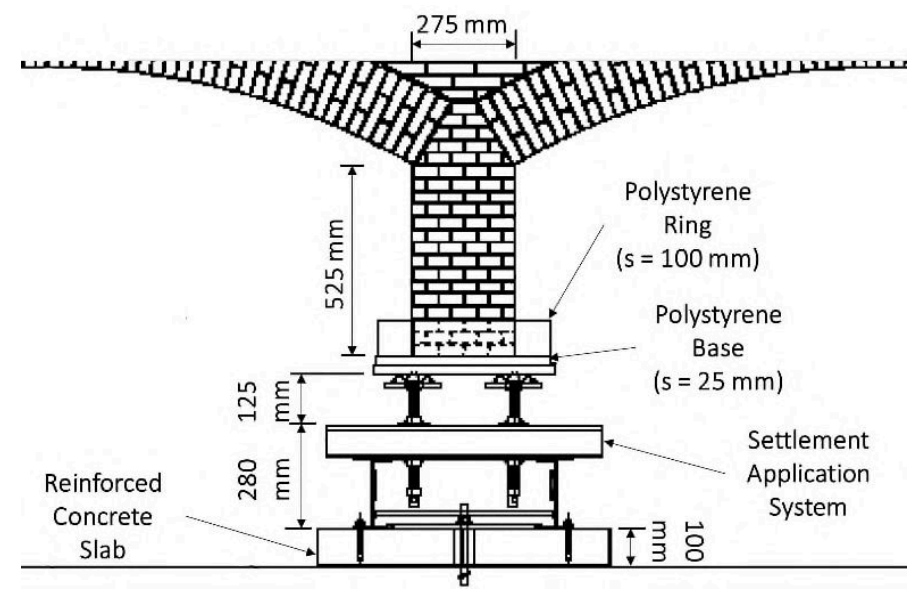

(b) 
Figure 9. (a) View of masonry arch bridge in the laboratory of Politecnico di Torino. Total bridge height $(\mathrm{H})$, length (L), and width (W) highlighted. The polystyrene layer is visible as the white bloc surrounding and beneath the base of the central pier, while the settlement application system is visible under the same. (b) geometric details of the central pier, settlement application system, and polystyrene layers.

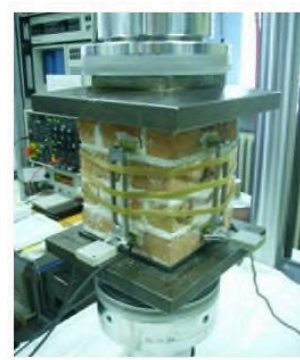

(a)

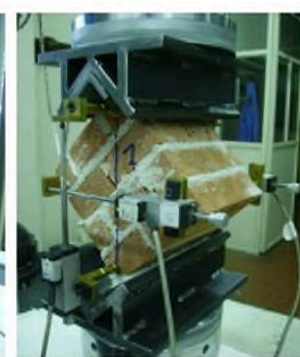

(b)

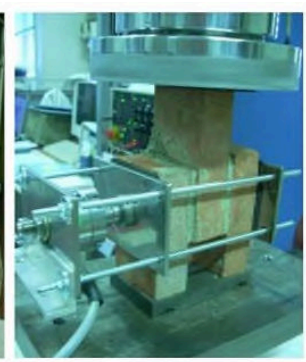

(c)

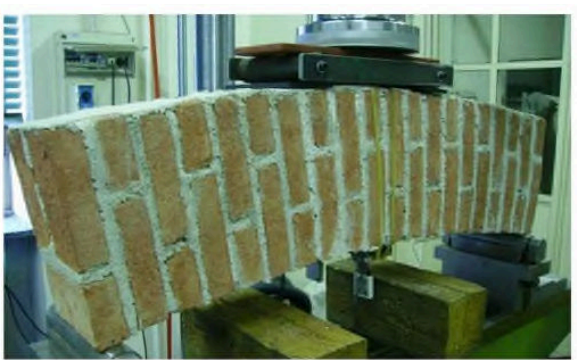

(d)

Figure 10. (a) The experimental setups for the destructive tests performed on the masonry samples: (a) axial compression on cubic samples; (b) diagonal compression on cubic samples; (c) shear tests on masonry triplets; (e) four points bending test on arch segments. Retrieved from Reference [43].

\begin{tabular}{|c|c|c|c|c|c|}
\hline $\begin{array}{c}\text { Total Bridge Height at } \\
\text { Deck 'H' }[\mathrm{mm}]\end{array}$ & $\mathbf{1 7 2 5}$ & Span Length $[\mathrm{mm}]$ & $\mathbf{2 0 0 0}$ & $\begin{array}{c}\text { Abutment Max Height } \\
\text { (external side) }[\mathrm{mm}]\end{array}$ & $\mathbf{1 2 0 0}$ \\
\hline $\begin{array}{c}\text { Total Bridge Length } \\
\text { 'L' [mm] }\end{array}$ & 5870 & Arch Rise [mm] & 268 & $\begin{array}{c}\text { Abutment Min Height } \\
\text { (internal side) }[\mathrm{mm}]\end{array}$ & 850 \\
\hline $\begin{array}{c}\text { Bridge Width 'W' } \\
{[\mathrm{mm}]}\end{array}$ & 1550 & $\begin{array}{c}\text { Central Pier Height } \\
{[\mathrm{mm}]}\end{array}$ & 525 & $\begin{array}{c}\text { Abutment Length } \\
{[\mathrm{mm}]}\end{array}$ & 1202 \\
\hline $\begin{array}{c}\text { Backfill Height at the } \\
\text { Crown [mm] }\end{array}$ & 360 & $\begin{array}{c}\text { Central Pier Length } \\
{[\mathrm{mm}]}\end{array}$ & 275 & $\begin{array}{c}\text { Abutment Width } \\
{[\mathrm{mm}]}\end{array}$ & 1600 \\
\hline
\end{tabular}

Table 4. Geometrical parameters of the masonry arch bridge (retrieved from Reference [43]). 


\begin{tabular}{|c|c|c|c|c|c|}
\hline Material & $\begin{array}{c}\mathbf{E} \\
{[\mathbf{M P a}]}\end{array}$ & $\begin{array}{c}\boldsymbol{v} \\
{[-]}\end{array}$ & $\begin{array}{c}\rho \\
{\left[\mathrm{kg} / \mathrm{m}^{3}\right]}\end{array}$ & $\begin{array}{c}\mathbf{V}_{\mathbf{p}} \\
{[\mathrm{m} / \mathrm{s}]}\end{array}$ & $\begin{array}{c}\mathbf{V}_{\mathrm{s}} \\
{[\mathrm{m} / \mathrm{s}]}\end{array}$ \\
\hline Reinforced concrete & 30000 & 0.15 & 2400 & 3633 & 2331 \\
\hline Masonry & 1500 & 0.20 & 1900 & 937 & 574 \\
\hline Backfill material & 50 & 0.10 & 2000 & 160 & 107 \\
\hline Concrete & 5000 & 0.15 & 2200 & 1549 & 994 \\
\hline
\end{tabular}

Table 5. Characteristics of the building materials.

\subsubsection{Scour Simulation}

The constraints applied at the central pier were intended to mimic the effects of scouring and undermining at its foundation. To this aim, experimental hydraulic investigations were conducted in the Department of Hydraulic Engineering at the Politecnico di Torino to estimate the soil erosion around and below the rectangular foundation, as detailed in Reference [43]. The correlation between the removed riverbed material and the corresponding pier displacements and rotations were then estimated through numerical analyses. The main aspects of these preliminary studies can be summarised as follow:

- A 32x160x580 mm parallelepiped was used as a scaled hydraulic model of the pier and fixed on a $58.5 \times 210 \times 32 \mathrm{~mm}$ foundation;

- The pier-foundation model was inserted in a flume test channel with rectangular section 500x580 mm (width x height), length $11.6 \mathrm{~m}$, and longitudinal slope $0.48 \%$, then dipped into non-cohesive sand with uniform mean diameter of $0.80 \mathrm{~mm}$ with different depths $(0$, 1.5 , or $2.5 \mathrm{~mm})$; 
- The three flume tests were performed with the following hydraulic parameters: water depth $215 \mathrm{~mm}$, constant flow $120 \mathrm{~m}^{3} / \mathrm{h}$, mean velocity $0.310 \mathrm{~m}^{3} / \mathrm{h}$, stream intensity 0.92, Froude number 0.214, and Reynolds number 0.072 ;

- The temporal evolution of the scour hole was acquired via image analysis, considering a laser projection for the soil profile (the experimental setup and an example of a resulting settlement profile are reported in Figure 11);

- The subsequent steps of erosion (and therefore of damage development) were defined accordingly to the evolution of the soil profile at fixed time steps;

- The measured portions of streambed material removed the foundation side were used to estimate the corresponding percentages of the polystyrene ring to be removed from the sides of the pier base at any damage step;

- The measured scour depths of the material removed underneath the model were used to estimate the corresponding foundation settlements, calculated at the four corners of the foundation. These settlements were adjusted via numerical simulations on a 3D finite element model (realised with the ADINA software) to rescale them to the structural model size and to adjust them for the different boundary conditions and the deformability of the polystyrene base.

The hydraulic tests returned results consistent with the expected outcomes, i.e. a larger settlement upstream with the consequent tilt of the foundation. The FE simulations allowed to preestimate the damage pattern and potential collapse mechanism induced by the prescribed displacement. These were found to be comparable to what observed in situ for similar structures [43] and match qualitatively the findings of other works reported in the scientific literature (e.g. in Reference [44] and [22]). It must be said that, from preliminary studies [42], it was found that the removal of the polystyrene ring surrounding the pier foundation did not cause any relevant frequency 
shift on its own. Without any rotation or displacement applied on the central pier, removing up to 30 $\mathrm{cm}$ of the ring layer induced a reduction of $0.27 \mathrm{~Hz}$ on the first natural frequency.

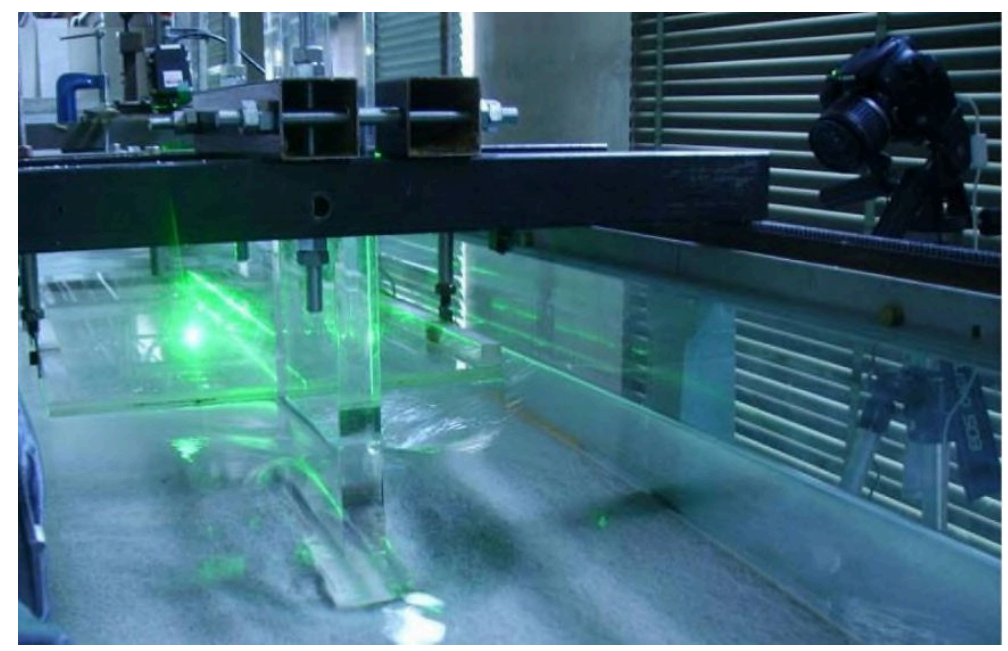

(a)

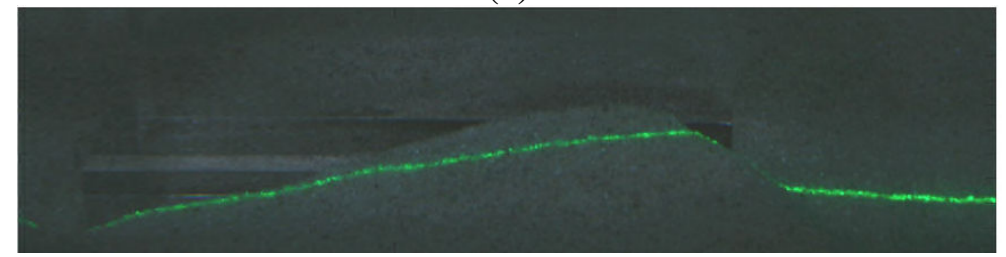

(b)

Figure 11. (a) experimental setup for the monitoring of the streambed scour with laser beam projection and video camera acquisition; (b) example of an acquired snapshot. Retrieved from Reference [43].

\subsection{Damage Scenarios and Experimental Campaigns}

Different damage steps have been applied to the structure by applying controlled settlements and rotations, jointly with polystyrene removal, accordingly with what observed from the hydraulic flume tests described in the previous Sections. The displacements were applied on the side of the settlement application system arbitrarily considered as upstream. The investigation reported here focused on the results of the third campaign, which is detailed in Table 6. Throughout the application of the consecutive damage steps (in a span of two months), it was visually observed that a crack 
pattern emerged, with a progressive partial detachment between the arches and the spandrel walls at their interface.

The excitation input was provided through hammer tests while the resulting outputs were acquired via 18 monoaxial PCB 3701G3FA3G Piezotronics accelerometers with a sensitivity of $1 \mathrm{~V} / \mathrm{g}$, a resolution of $30 \mu \mathrm{g}$, a measurement range of $\pm 3 \mathrm{~g}$, and a weight of $17.5 \mathrm{~g}$. Two different sensor placements, named setup \#1 and \#2 and portrayed in Figure 12, were used for each damage step. Acquisitions from both setups have been exploited for system identification to enhance the research of different modes. This also allowed to cross-validate the recurrence of the different vibrational modes varying the acquisition setups, facilitating the separation between real and spurious modes. Sampling frequency was set to $400 \mathrm{~Hz}$, with a frequency resolution of $0.017 \mathrm{~Hz}$. The details of the hammer impacts can be found in Appendix A. Only the most significant acquisitions and impacts of the hammer were selected, as the quality of the acquisitions differs for the point and direction of hammer impact which consequently excites different modes. For instance, the acquisitions orthogonal to the arch (\#17-\#30 as reported in Table A.1 from Appendix A) excite better vertical or longitudinal modes, while the transversal at the pier ones (\#6-\#10) excite more the lateral modes. The acquisitions close to the abutments (\#1-\#2) are affected from a high level of noise and so they were not used for system identification. All the results are expressed in terms of accelerance FRFs (expressed as the ratio of acceleration output $\left(\mathrm{m}^{2} / \mathrm{s}\right)$ over force input $(\mathrm{N})$ ).

As expected, the presence of structural nonlinearities was confirmed from the recorded output signals. In this sense, the magnitude-squared coherence function [45] was applied as a nonlinearity test (as suggested by Reference [46], Chapter 2.5), since it departs from the unity whenever a nonlinear term is added to the investigated system. As can be seen in Figure 13, the coherence falls well below the unity for almost all channels and at several frequency bands. As 
mentioned previously, these effects are inherent in the material (where they are generally dominated by the nonlinear behaviour at the brick-mortar interfaces) and increased by the developing cracks.

\begin{tabular}{|c|c|c|c|}
\hline 3rd Experimental campaign & Settlement at the & Rotation at the & Polystyrene \\
central pier [mm] & central pier [rad] & removed [\%] \\
\hline DS4 (end of the 2nd & 2.25 & $1.0110^{-3}$ & 47 \\
\hline Experimental Campaign) & & & 56 \\
\hline DS6 (Post Relaxation) & 2.25 & $1.2310^{-3}$ & 72 \\
\hline DS7 & 2.8 & $1.2310^{-3}$ & 81 \\
\hline DS8 & 3.6 & $1.2710^{-3}$ & 100 \\
\hline DS9 & 4.7 & $1.3010^{-3}$ & 91 \\
\hline
\end{tabular}

Table 6. Description of the third experimental campaign.
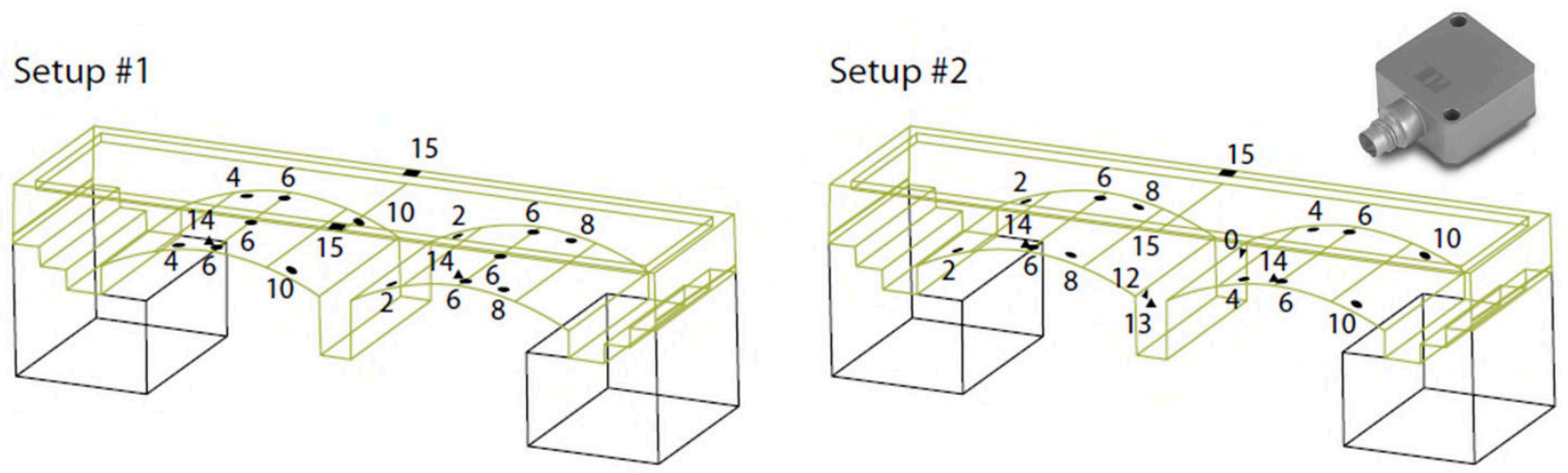

Figure 12. Position of the channels according to Setup \#1 and Setup \#2. An example of PCB 3701G3FA3G accelerometer is shown in the top right corner (www.PCB.com). Adapted from Reference [41]. 


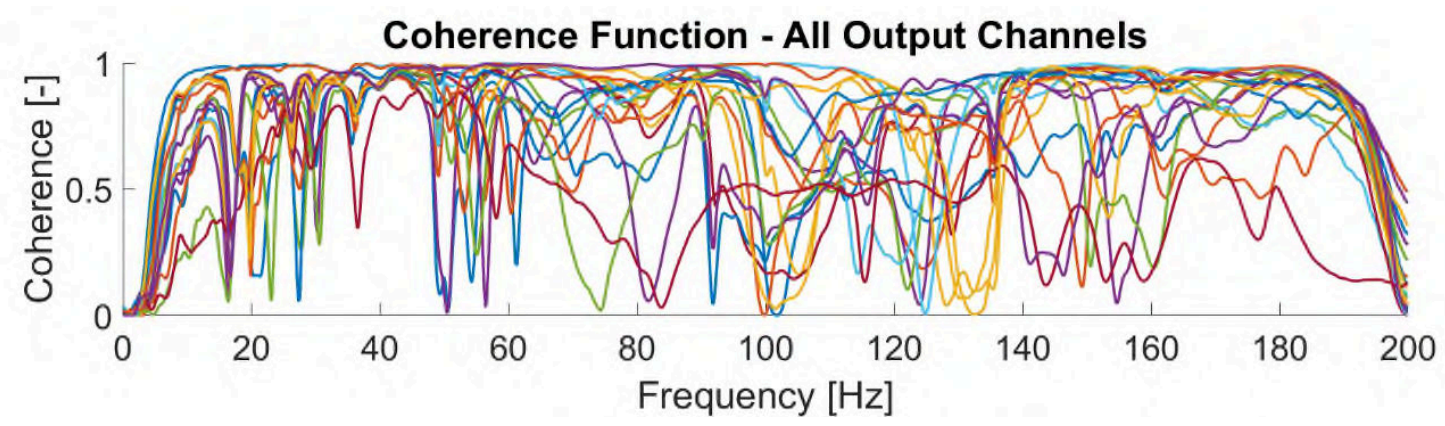

Figure 13. The magnitude-squared coherence functions defined between the output channels and the input (recorded from the instrumented impact hammer). Data recorded from DS4.

\subsection{Results}

The identification was focused of the first four modes (respectively, the first vertical, longitudinal, lateral and torsional vibrational mode) since they were considered the most relevant ones for the dynamic characterisation of the structure. By way of illustration, the fitting of the data from the Setup $\# 2$ is represented in Figure 14.

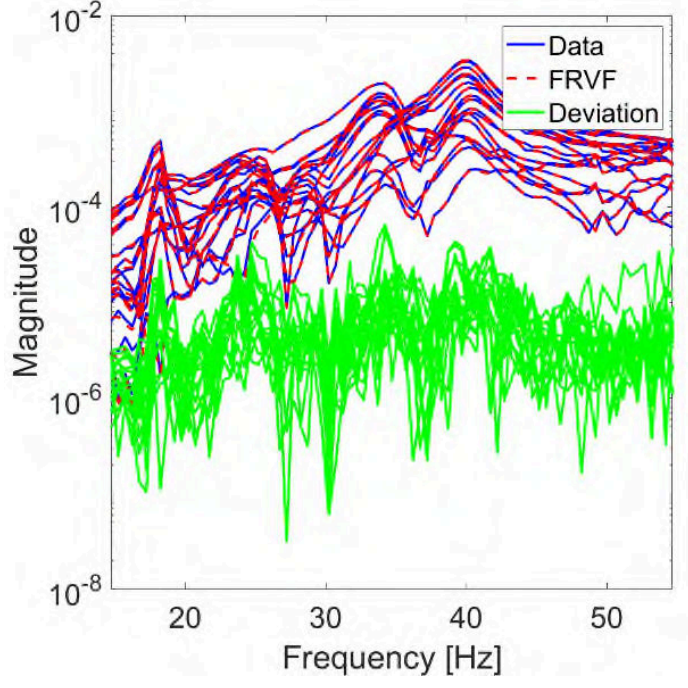

(a)

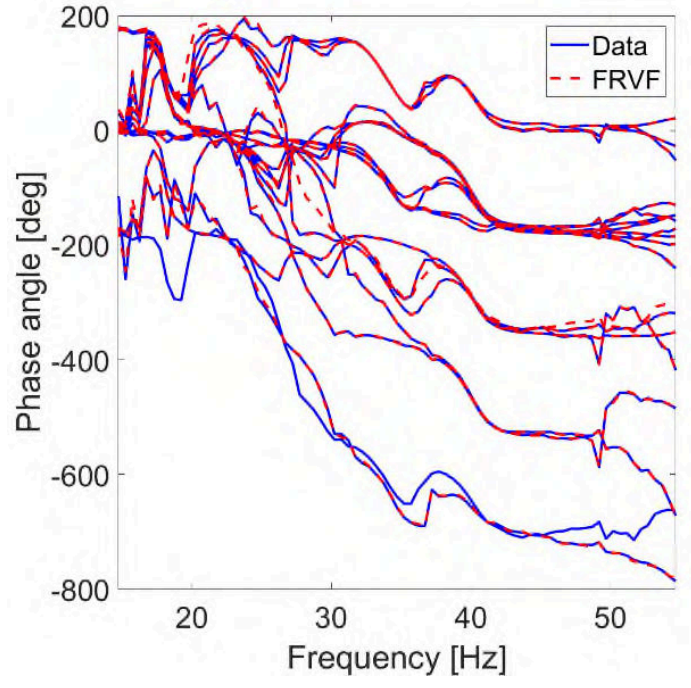

(b) 
Figure 14. Masonry bridge: SIMO with 18 output channels (setup \#2). (a): Plot of the absolute value of gain. (b): phase angle.

The stabilisation diagrams and frequency-damping plots, as described in Reference [47] and [48], can be defined by running the FRVF identification procedure with increasing model order $\mathrm{N}$, to assess the performance of the method and the stability of the identified modal parameters. The stable and unstable poles are determined based on different stabilisation criterion, in terms of natural frequency, modal damping and MAC, for a range of model orders varying from $\mathrm{N}_{\min }=50$ to $\mathrm{N}_{\max }=$ 100. The difference in natural frequency $\delta f$, difference in modal damping $\delta \zeta$, and the Modal Assurance Criterion (MAC) have been used as stabilisation criteria to select the stable modes:

$$
\delta f \leq 0.01, \quad \delta \zeta \leq 0.1, \quad(1-M A C) \leq 0.95(15)
$$

Poles with negative damping or $\zeta$ larger than $10 \%$ were also automatically discarded. In Figure 15 the stabilisation diagram for Setup 1 of Step DS4 is reported. The Power Spectral Density (PSD) curves of a single channel are shown for comparison. It is clear how, for the same stabilization settings, the ERA results are affected by many spurious poles. On the other hand, the FRVF approach identifies quite consistently the first vibrational mode at circa $18 \mathrm{~Hz}$. It struggles to isolate the second mode at circa $28 \mathrm{~Hz}$ (also due to the specific sensor setup utilised [43]), while it returns very stable identifications for both the $3^{\text {rd }}$ and the $4^{\text {th }}$ mode $(\sim 34 \mathrm{~Hz}$ and $\sim 40 \mathrm{~Hz}$, in this order). 

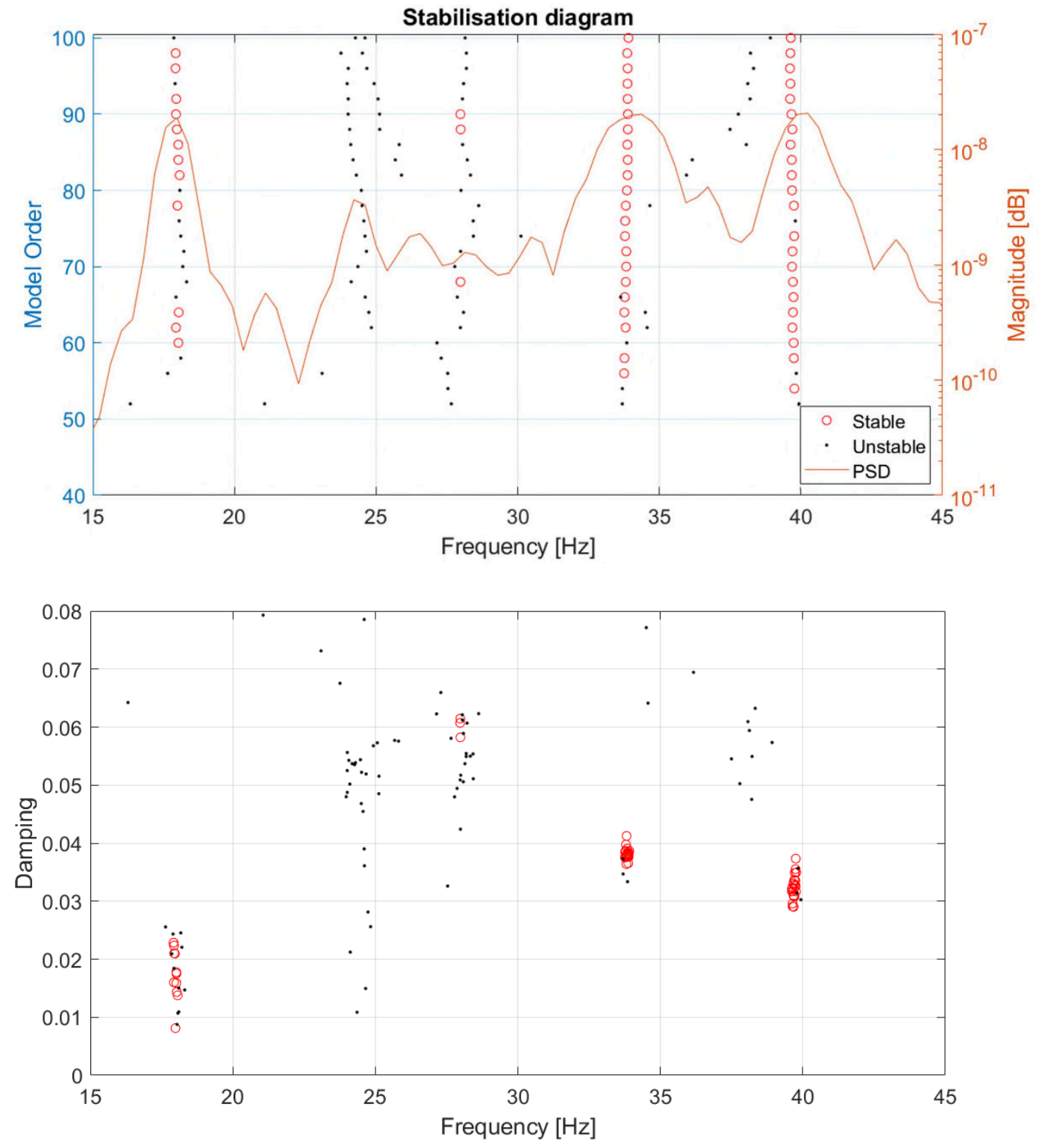

(a) 

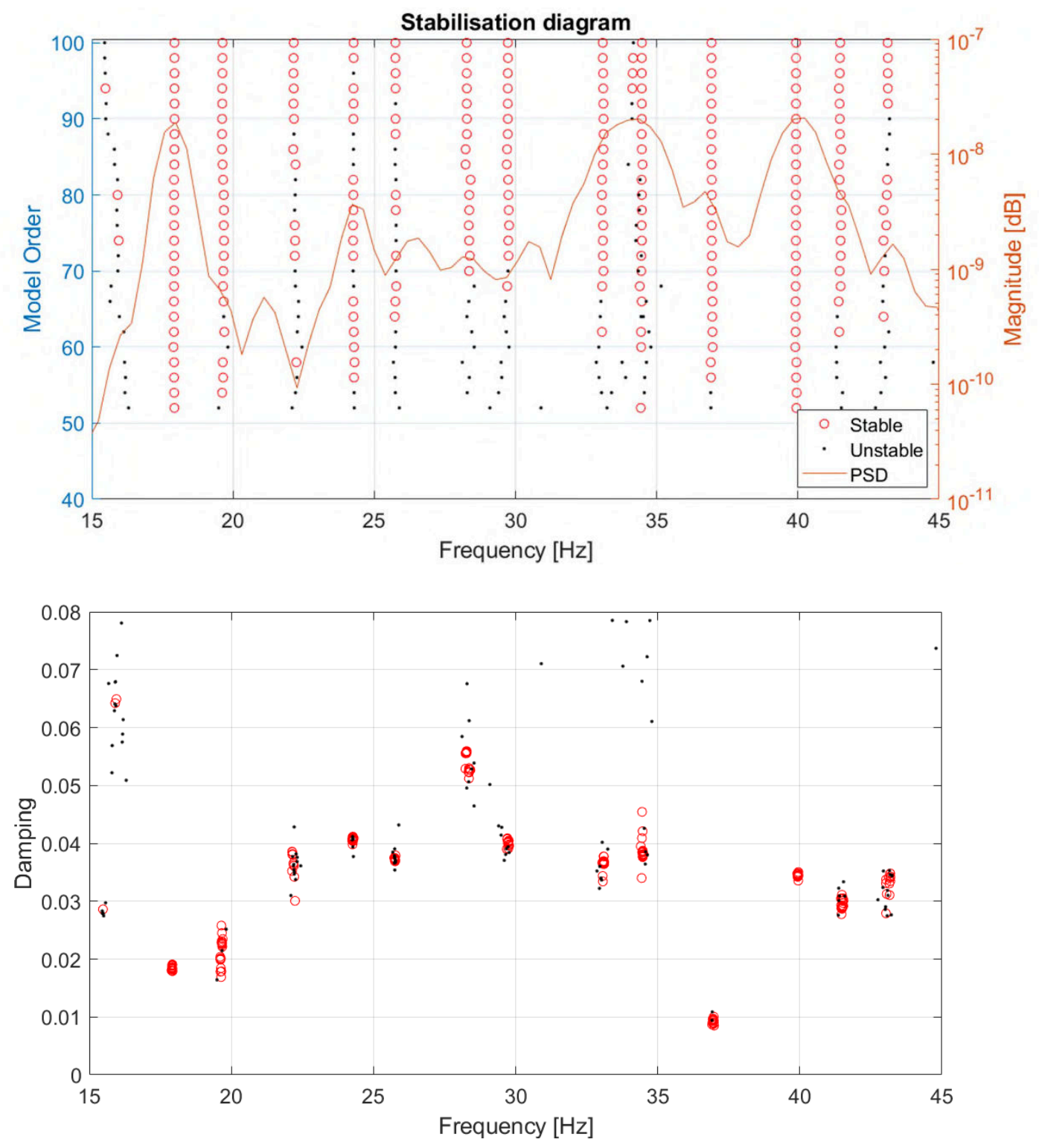

(b)

Figure 15. Stabilisation and frequency-damping diagrams: (a) FRVF (b) ERA.

The whole non-optimised MATLAB code for the FRVF elapsed 16.821 seconds to compute and process all the model orders reported in Figure 15. For the same range of model orders, the ERA returned a much less clean stabilisation diagram, with many spurious poles (which need to be removed by hand in post-processing), in 21.35 seconds. 
The evolution of the four natural frequencies of interest along the whole third experimental campaign is plotted in Figure 16. The values are compared in Table 7 against the identification obtained from ERA. The reported values have been averaged over seven hammer consecutive hammer blows, recorded (for any damage step) one after the other. As before, the standard deviation values reported in brackets. The shift in the damping ratios is reported as well since it can be considered a damage-sensitive feature [49], even if it is well-known that it is more difficult to estimate with precision and subject to larger variance, which hampers is usefulness in practical terms [50]. The initial frequency shift with no settlement applied is due to the differences between the measurements taken at the end of the second campaign and the beginning of the third one, 17 months later. These changes are almost surely due to the variation of the boundary conditions that occurred during this period. After the end of the previous experimental campaign, the central pier was partially suspended, due to the relatively sudden lowering of the plate supporting it. In between the $2^{\text {nd }}$ and the $3^{\text {rd }}$ campaign, the pier settled, causing an increase in its vertical stiffness. In turn, this caused the unexpected recovery of the first natural frequency, which corresponds to the vertical bending, as the recovered stiffness outweighed the induced damage. This recovery did not affect significantly the other vibrational modes (mainly the longitudinal and lateral bending and torsion), which instead were more responsive to other phenomena occurring during the relaxation (most probably, further crack development in the arch barrels due to long-term settling) [41].

Subsequently, the frequencies decreased for an increased settlement of the pier, almost linearly. Since the mass of the test structure is unchanged, these trends can be linked directly to a decrease in the system's stiffness. Only in Step \#6, the fourth natural frequency was overestimated and the first and the second ones were probably slightly underestimated; this can be due to the presence of measurements noise. 


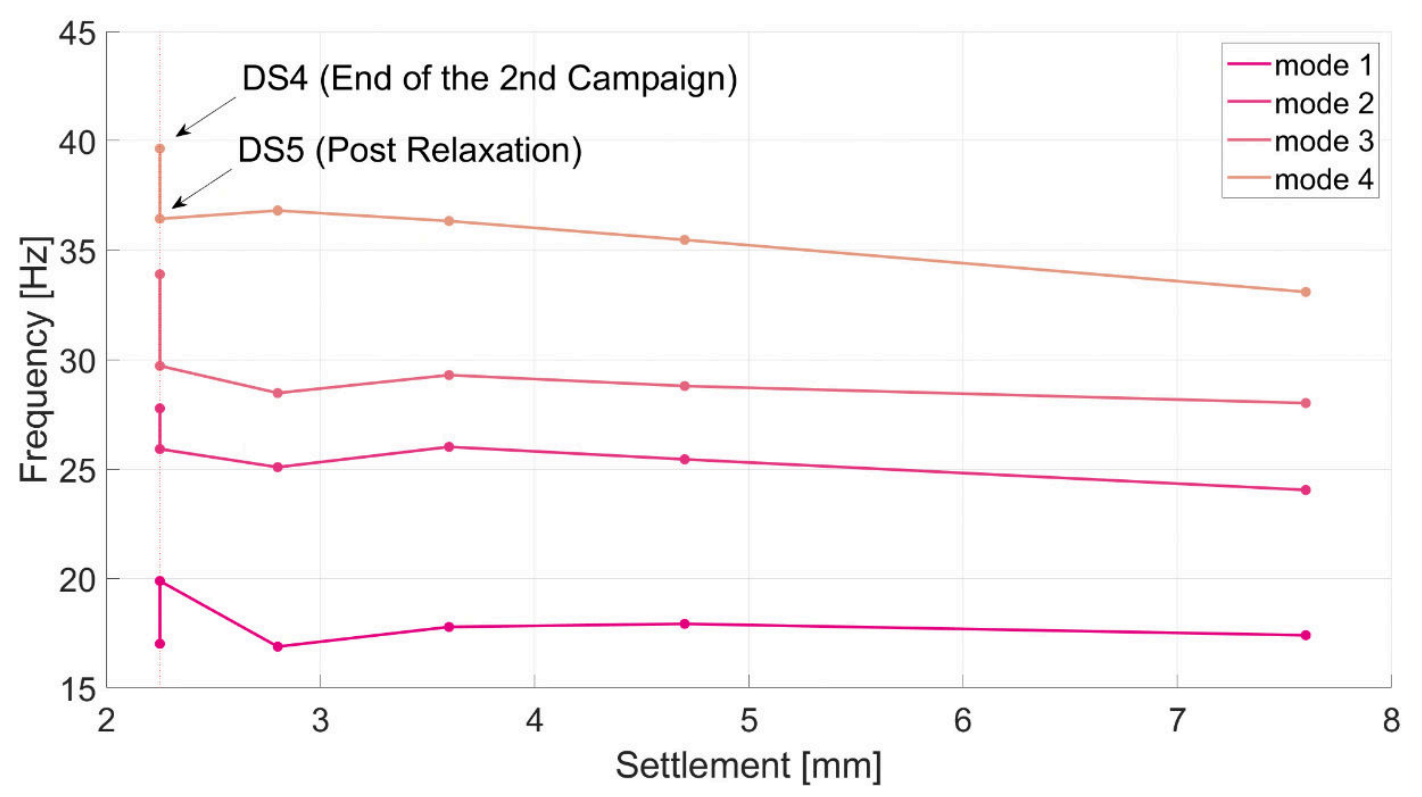

Figure 16. The trend of the first four natural frequencies accordingly to the displacement imposed at the central pier.

\begin{tabular}{|c|c|c|c|c|c|c|c|c|}
\hline \multicolumn{9}{|c|}{ 3rd Experimental campaign } \\
\hline \multirow{3}{*}{$\begin{array}{c}\text { Damage } \\
\text { Step }\end{array}$} & \multicolumn{5}{|c|}{ Natural Frequencies [Hz] } & \multicolumn{3}{|c|}{ Damping Ratios [-] } \\
\hline & \multicolumn{8}{|c|}{ FRVF } \\
\hline & $\# 1$ & $\# 2$ & \#3 & $\# 4$ & $\# 1$ & $\# 2$ & $\# 3$ & $\# 4$ \\
\hline $\begin{array}{l}\text { End of } 2^{\text {nd }} \\
\text { Campaign }\end{array}$ & $\begin{array}{l}17.01 \\
(0.21)\end{array}$ & $\begin{array}{l}27.77 \\
(0.20)\end{array}$ & $\begin{array}{l}33.90 \\
(0.25)\end{array}$ & $\begin{array}{l}39.64 \\
(0.27)\end{array}$ & $\begin{array}{c}0.01567 \\
(0.015)\end{array}$ & $\begin{array}{l}0.0619 \\
(0.014)\end{array}$ & $\begin{array}{l}0.0412 \\
(0.005)\end{array}$ & $\begin{array}{l}0.0355 \\
(0.003)\end{array}$ \\
\hline $\begin{array}{c}\text { DS5 (Post } \\
\text { Relaxation) }\end{array}$ & $\begin{array}{l}19.88 \\
(0.20)\end{array}$ & $\begin{array}{l}25.91 \\
(0.16)\end{array}$ & $\begin{array}{l}29.72 \\
(0.28)\end{array}$ & $\begin{array}{l}36.43 \\
(0.24)\end{array}$ & $\begin{array}{l}0.0318 \\
(0.006)\end{array}$ & $\begin{array}{l}0.0324 \\
(0.006)\end{array}$ & $\begin{array}{l}0.0125 \\
(0.004)\end{array}$ & $\begin{array}{l}0.0365 \\
(0.003)\end{array}$ \\
\hline DS6 & $\begin{array}{l}16.88 \\
(0.18)\end{array}$ & $\begin{array}{l}25.08 \\
(0.17)\end{array}$ & $\begin{array}{l}28.47 \\
(0.23)\end{array}$ & $\begin{array}{l}36.81 \\
(0.35)\end{array}$ & $\begin{array}{l}0.0202 \\
(0.007)\end{array}$ & $\begin{array}{l}0.0114 \\
(0.008)\end{array}$ & $\begin{array}{l}0.0218 \\
(0.004)\end{array}$ & $\begin{array}{l}0.0244 \\
(0.011)\end{array}$ \\
\hline
\end{tabular}




\begin{tabular}{|c|c|c|c|c|c|c|c|c|}
\hline DS7 & $\begin{array}{l}17.78 \\
(0.11)\end{array}$ & $\begin{array}{l}26.01 \\
(0.15)\end{array}$ & $\begin{array}{l}29.29 \\
(0.27)\end{array}$ & $\begin{array}{l}36.33 \\
(0.31)\end{array}$ & $\begin{array}{l}0.0256 \\
(0.005)\end{array}$ & $\begin{array}{l}0.0211 \\
(0.007)\end{array}$ & $\begin{array}{l}0.0191 \\
(0.004)\end{array}$ & $\begin{array}{l}0.0207 \\
(0.002)\end{array}$ \\
\hline DS8 & $\begin{array}{l}17.92 \\
(0.09)\end{array}$ & $\begin{array}{l}25.44 \\
(0.07)\end{array}$ & $\begin{array}{l}28.79 \\
(0.15)\end{array}$ & $\begin{array}{l}35.47 \\
(0.22)\end{array}$ & $\begin{array}{l}0.0279 \\
(0.004)\end{array}$ & $\begin{array}{l}0.0436 \\
(0.002)\end{array}$ & $\begin{array}{l}0.0471 \\
(0.005)\end{array}$ & $\begin{array}{l}0.0388 \\
(0.004)\end{array}$ \\
\hline DS9 & $\begin{array}{l}17.40 \\
(0.12)\end{array}$ & $\begin{array}{l}24.04 \\
(0.20)\end{array}$ & $\begin{array}{l}28.01 \\
(0.23)\end{array}$ & $\begin{array}{r}33.09 \\
(0.11)\end{array}$ & $\begin{array}{l}0.0201 \\
(0.003)\end{array}$ & $\begin{array}{l}0.0457 \\
(0.001)\end{array}$ & $\begin{array}{l}0.0355 \\
(0.006)\end{array}$ & $\begin{array}{l}0.0536 \\
(0.005)\end{array}$ \\
\hline & \multicolumn{8}{|c|}{ ERA } \\
\hline $\begin{array}{l}\text { End of } 2^{\text {nd }} \\
\text { Campaign }\end{array}$ & $\begin{array}{l}17.63 \\
(0.28)\end{array}$ & $\begin{array}{l}28.21 \\
(0.22)\end{array}$ & $\begin{array}{l}34.07 \\
(0.29)\end{array}$ & $\begin{array}{l}39.72 \\
(0.26)\end{array}$ & $\begin{array}{l}0.0278 \\
(0.013)\end{array}$ & $\begin{array}{l}0.0463 \\
(0.016)\end{array}$ & $\begin{array}{l}0.0365 \\
(0.006)\end{array}$ & $\begin{array}{l}0.0322 \\
(0.005)\end{array}$ \\
\hline $\begin{array}{c}\text { DS5 (Post } \\
\text { Relaxation) }\end{array}$ & $\begin{array}{l}19.16 \\
(0.22)\end{array}$ & $\begin{array}{l}26.62 \\
(0.18)\end{array}$ & $\begin{array}{l}29.64 \\
(0.33)\end{array}$ & $\begin{array}{l}36.23 \\
(0.25)\end{array}$ & $\begin{array}{l}0.0328 \\
(0.005)\end{array}$ & $\begin{array}{l}0.0221 \\
(0.006)\end{array}$ & $\begin{array}{l}0.0187 \\
(0.005)\end{array}$ & $\begin{array}{l}0.0421 \\
(0.006)\end{array}$ \\
\hline DS6 & $\begin{array}{l}16.77 \\
(0.16)\end{array}$ & $\begin{array}{l}25.48 \\
(0.19)\end{array}$ & $\begin{array}{l}28.89 \\
(0.24)\end{array}$ & $\begin{array}{l}36.92 \\
(0.33)\end{array}$ & $\begin{array}{l}0.0267 \\
(0.008)\end{array}$ & $\begin{array}{l}0.0207 \\
(0.004)\end{array}$ & $\begin{array}{l}0.0237 \\
(0.007)\end{array}$ & $\begin{array}{l}0.0221 \\
(0.012)\end{array}$ \\
\hline DS7 & $\begin{array}{l}16.78 \\
(0.12)\end{array}$ & $\begin{array}{l}25.68 \\
(0.14)\end{array}$ & $\begin{array}{l}28.77 \\
(0.28)\end{array}$ & $\begin{array}{l}36.42 \\
(0.27)\end{array}$ & $\begin{array}{l}0.0116 \\
(0.006)\end{array}$ & $\begin{array}{l}0.0229 \\
(0.005)\end{array}$ & $\begin{array}{l}0.0177 \\
(0.005)\end{array}$ & $\begin{array}{l}0.0158 \\
(0.002)\end{array}$ \\
\hline DS8 & $\begin{array}{l}17.91 \\
(0.05)\end{array}$ & $\begin{array}{l}26.00 \\
(0.06)\end{array}$ & $\begin{array}{l}28.83 \\
(0.16)\end{array}$ & $\begin{array}{l}36.74 \\
(0.19)\end{array}$ & $\begin{array}{l}0.0275 \\
(0.002)\end{array}$ & $\begin{array}{l}0.0498 \\
(0.003)\end{array}$ & $\begin{array}{l}0.0480 \\
(0.003)\end{array}$ & $\begin{array}{l}0.0402 \\
(0.002)\end{array}$ \\
\hline DS9 & $\begin{array}{l}17.05 \\
(0.11)\end{array}$ & $\begin{array}{l}23.24 \\
(0.18)\end{array}$ & $\begin{array}{l}27.77 \\
(0.25)\end{array}$ & $\begin{array}{l}35.36 \\
(0.14)\end{array}$ & $\begin{array}{l}0.0195 \\
(0.004)\end{array}$ & $\begin{array}{l}0.0465 \\
(0.003)\end{array}$ & $\begin{array}{l}0.0415 \\
(0.004)\end{array}$ & $\begin{array}{l}0.0704 \\
(0.007)\end{array}$ \\
\hline
\end{tabular}

Table 7. Frequency and damping ratio shifts for increasing settlements.

Finally, the obtained mode shapes have been plotted and compared to the same as obtained by applying the Eigensystem Realization Algorithm (ERA) method in Figure 17. A comparison in terms of the diagonal elements of the MAC matrix is reported in Table 8 . One can see that the 1st and 4th mode have a degree of similarity equal or larger than $90 \%$ for all the damage steps, while 
the lateral and the longitudinal bending modes have slightly lower MAC values, even if showing always good accordance between the results of the two methods.

As a concluding remark, there are no technical limitations for applying the proposed approach for the in situ continuous monitoring of real size masonry arc bridges. It is however necessary to remark that, in real-life situations, frequency shifts alone could be not sufficient to unequivocally assess the damaged conditions. For instance, the stiffness variations induced by crack development can be difficultly isolated from the influence of flexible foundation conditions and soilfoundation-structure interactions [51]. Nevertheless, the proposed technique is found able to capture the modal characteristics (natural frequency, damping ratios, and mode shapes) of the target system reliably and efficiently. If properly depurated from environmental effects, time-varying soil conditions, operational conditions, and other damage-unrelated variations of the modal parameters [52], these can be exploited for state-of-the-art SHM as e.g. performed in Reference [7].

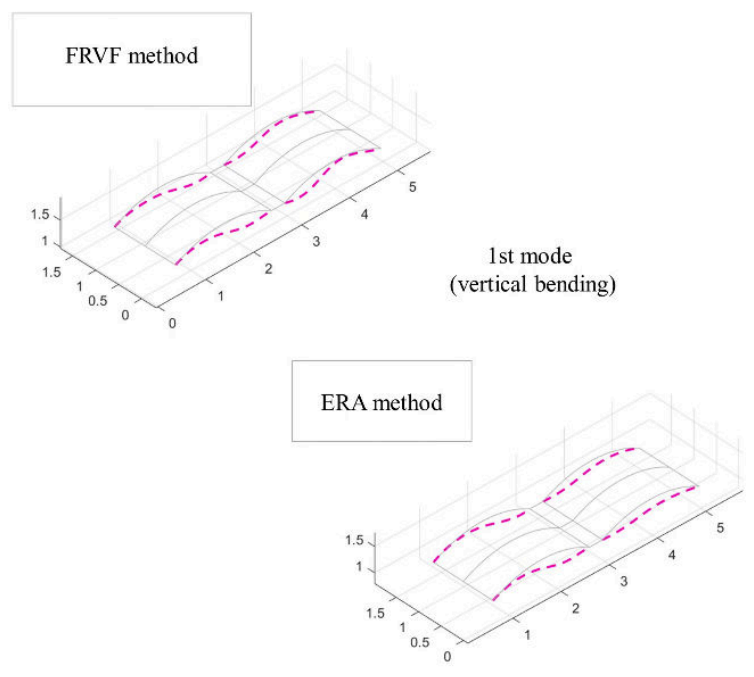

(a)

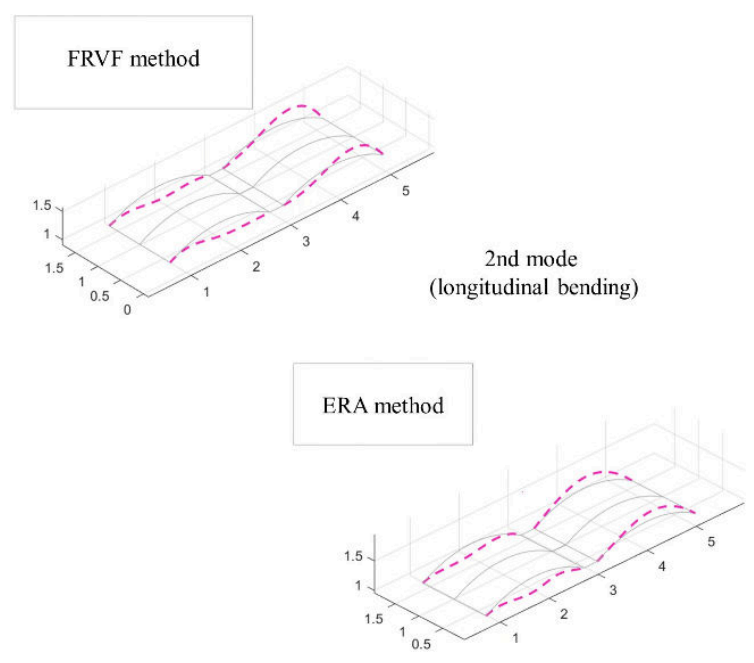

(b) 


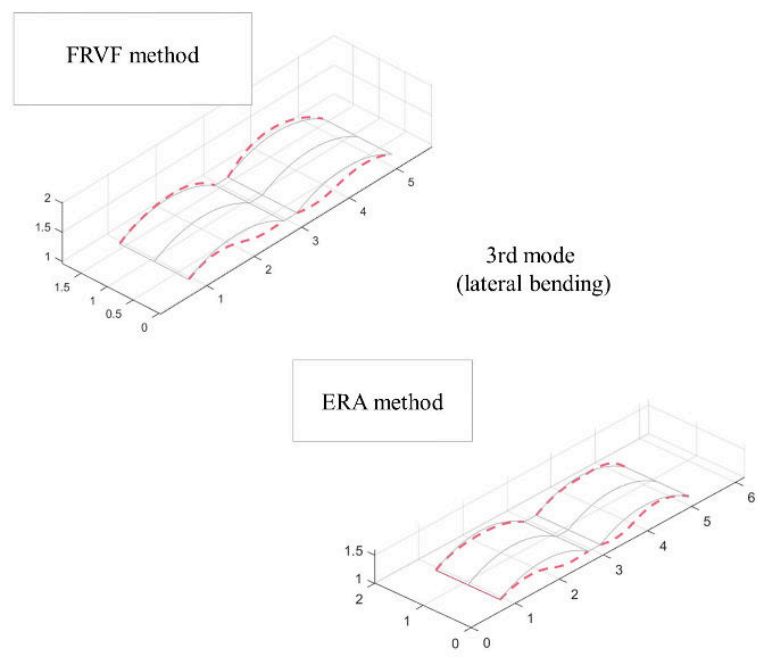

(c)

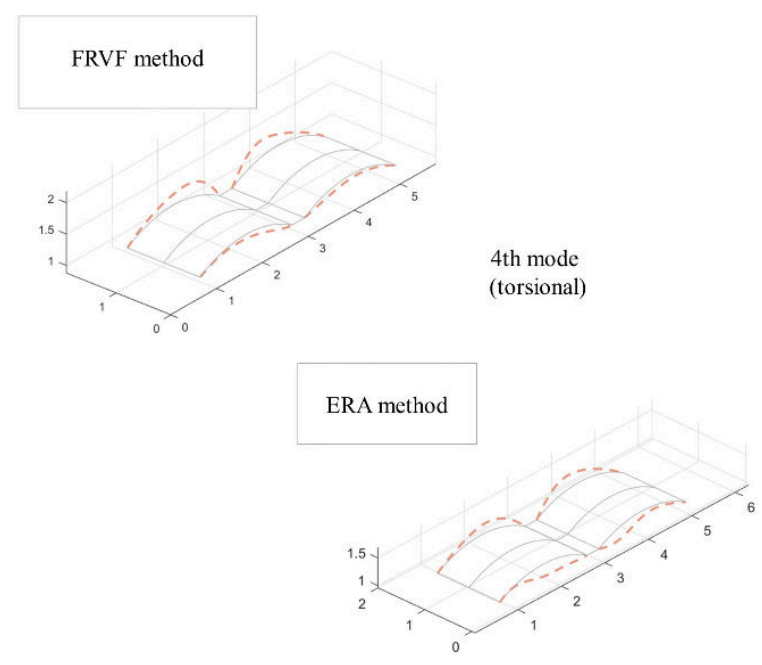

(d)

Figure 17. Experimental modal shapes: (a) first mode; (b) second mode; (c) third mode; and (d) fourth mode. Left: results obtained from the FRVF; right: obtained from ERA. Thick dashed lines: edges of the deformed shape. Thin solid lines: undeformed shape.

\begin{tabular}{|c|c|c|c|c|}
\hline \multicolumn{3}{|c|}{ 3rd Experimental campaign } \\
\hline Damage Step & \multicolumn{4}{|c|}{ MAC [-] } \\
\hline & Mode & Mode & Mode & Mode \\
& $\# 1$ & $\# 2$ & $\# 3$ & $\# 4$ \\
\hline DS4 (End of & 0.93 & 0.84 & 0.83 & 0.94 \\
2nd Campaign) & & & & \\
\hline DS5 (Post & 0.95 & 0.85 & 0.89 & 0.98 \\
Relaxation) & & & & 0.94 \\
\hline DS6 & 0.92 & 0.79 & 0.85 & \\
\hline
\end{tabular}




\begin{tabular}{|c|c|c|c|c|}
\hline DS7 & 0.92 & 0.80 & 0.89 & 0.90 \\
\hline DS8 & 0.96 & 0.78 & 0.77 & 0.85 \\
\hline DS9 & 0.92 & 0.90 & 0.81 & 0.85 \\
\hline
\end{tabular}

Table 8. MAC between mode shapes as obtained from ERA and FRVF.

\section{Discussion and Conclusions.}

For SHM purposes, it is mandatory to model properly the dynamic behaviour of the structure of interest. This helps in defining an efficient monitoring strategy, able to provide useful information about the building's current conditions. This aspect is even more important for historical masonry constructions, which are particularly susceptible to damage in case of extreme events (especially earthquakes) and naturally subject to the deleterious effects of ageing.

The Experimental Modal Analysis is a well-known tool, useful to characterise the structure from a dynamic point of view in a reliable way. In this context, this paper presented an application of the Fast Relaxed Vector Fitting (FRVF), an approach inherited from the macro modelling of electrical circuits and recently proposed for mechanical systems, to the structural identification of systems with increasing damage. The method was firstly tested for the fitting of synthetic data and then validated on two laboratory case studies: a multi-damaged aluminium box beam, developed at Cranfield University, and a 1:2 scale masonry bridge, built in the facilities of the Politecnico di Torino. These two experiments were intended, respectively, as a preliminary validation on a simple, linearly behaving structure with artificially inserted and controlled damage (two straight u-shaped slots) and as an example of application to a much more compelling masonry structure. For the masonry bridge, the incremental damage (settlement cracks) was experimentally induced by the scouring emulated at the mid-length pier. The purpose was to test the algorithm to fitting a transfer function with a high presence of measurement noise and noise-like disturbances induced 
by the masonry nonlinearities. These latter were caused by the composite material (Portland mortar and bricks), with its internal texture and local irregularities, and by the developing cracks. The main difficulties of this experimental case study resided not only in its nonlinearly behaving material but also in its large and realistic scale and mass and its structural complexity. These are representative of an application to real-scale structures.

The FRVF technique has therefore been proved as a viable, efficient, and robust tool for the identification of the modal parameters of a target structure. With all the needed precautions related to the use of modal parameters and their variations for anomaly detection, these identified features can be exploited for the assessment of damage in masonry buildings and structures, especially for the ones of high cultural and architectural relevance. This validation has been performed through a comparison with a well-established time-domain technique, specifically, the Eigensystem Realization Algorithm. When compared to this classic approach, the FRVF proved to be less sensitive to the measurement noise and nonlinear distortions while being faster and less computationally demanding.

\section{Acknowledgements}

The authors wish to thank Prof S. Grivet-Talocia of the Department of Electronics and Telecommunications of Politecnico di Torino for his help and precious advice. The authors would also like to thank the Dynamic Research group of the Department of Structural and Geotechnical Engineering for assisting in the data generation used for the masonry arch bridge case study (specifically Prof R. Ceravolo, Dr A. Quattrone, and Dr G. Ruocci). 


\section{References}

[1] Cavalagli N, Comanducci G, Ubertini F. Earthquake-Induced Damage Detection in a Monumental Masonry Bell-Tower Using Long-Term Dynamic Monitoring Data. J Earthq Eng 2018;22:96-119. https://doi.org/10.1080/13632469.2017.1323048.

[2] Matta E, Ceravolo R, De Stefano A, Quattrone A, Zanotti Fragonara L. Structural system identification in the presence of resonant non-structural appendages 2012.

[3] Heyman J. The stone skeleton: structural ... - Google Books. Cambridge University Press; 1997.

[4] Alberto A, Antonaci P, Valente S. Damage analysis of brick-to-mortar interfaces. Procedia Eng., vol. 10, Elsevier Ltd; 2011, p. 1151-6. https://doi.org/10.1016/j.proeng.2011.04.191.

[5] Manos GC, Simos N, Kozikopoulos E. The Structural Performance of Stone-Masonry Bridges. Struct. Bridg. Eng., InTech; 2016. https://doi.org/10.5772/64752.

[6] De Stefano A, Matta E, Clemente P. Structural health monitoring of historical heritage in Italy: some relevant experiences. J Civ Struct Heal Monit 2016;6:83-106. https://doi.org/10.1007/s13349-016-0154-y.

[7] Pecorelli ML, Ceravolo R, Epicoco R. An Automatic Modal Identification Procedure for the Permanent Dynamic Monitoring of the Sanctuary of Vicoforte. Int J Archit Herit 2018. https://doi.org/10.1080/15583058.2018.1554725.

[8] Azzara RM, de Falco A, Girardi M, Pellegrini D. Ambient vibration recording on the maddalena bridge in borgo a Mozzano (Italy): Data analysis. Ann Geophys 2017;60. https://doi.org/10.4401/ag-7159.

[9] Conde B, Drosopoulos GA, Stavroulakis GE, Riveiro B, Stavroulaki ME. Inverse analysis of masonry arch bridges for damaged condition investigation: Application on Kakodiki bridge. Eng Struct 2016;127:388-401. https://doi.org/10.1016/j.engstruct.2016.08.060.

[10] Conde B, Ramos LF, Oliveira D V., Riveiro B, Solla M. Structural assessment of masonry arch bridges by combination of non-destructive testing techniques and three-dimensional numerical modelling: Application to Vilanova bridge. Eng Struct 2017;148:621-38. https://doi.org/10.1016/j.engstruct.2017.07.011.

[11] De Falco A, Girardi M, Pellegrini D, Robol L, Sevieri G. Model parameter estimation using Bayesian and deterministic approaches: The case study of the Maddalena Bridge. Procedia 
Struct. Integr., vol. 11, Elsevier B.V.; 2018, p. 210-7.

https://doi.org/10.1016/j.prostr.2018.11.028.

[12] Gönen S, Soyöz S. Seismic analysis of a masonry arch bridge using multiple methodologies. Eng Struct 2021;226:111354. https://doi.org/10.1016/j.engstruct.2020.111354.

[13] Han Q, Xu J, Carpinteri A, Lacidogna G. Localization of acoustic emission sources in structural health monitoring of masonry bridge. Struct Control Heal Monit 2015;22:314-29. https://doi.org/10.1002/stc.1675.

[14] Manos GC, Pitilakis KD, Sextos AG, Kourtides V, Soulis V, Thauampteh J. Field Experiments for Monitoring the Dynamic Soil-Structure-Foundation Response of a BridgePier Model Structure at a Test Site. J Struct Eng 2015;141:D4014012. https://doi.org/10.1061/(ASCE)ST.1943-541X.0001154.

[15] Simos N, Manos GC, Kozikopoulos E. Near- and far-field earthquake damage study of the Konitsa stone arch bridge. Eng Struct 2018;177:256-67. https://doi.org/10.1016/j.engstruct.2018.09.072.

[16] Sánchez-Aparicio LJ, Bautista-De Castro Á, Conde B, Carrasco P, Ramos LF. Nondestructive means and methods for structural diagnosis of masonry arch bridges. Autom Constr 2019;104:360-82. https://doi.org/10.1016/j.autcon.2019.04.021.

[17] Pepi C, Gioffrè M, Comanducci G, Cavalagli N, Bonaca A, Ubertini F. Dynamic characterization of a severely damaged historic masonry bridge. Procedia Eng., vol. 199, Elsevier Ltd; 2017, p. 3398-403. https://doi.org/10.1016/j.proeng.2017.09.579.

[18] Roselli I, Malena M, Mongelli M, Cavalagli N, Gioffrè M, De Canio G, et al. Health assessment and ambient vibration testing of the "Ponte delle Torri" of Spoleto during the 2016-2017 Central Italy seismic sequence. J Civ Struct Heal Monit 2018;8:199-216. https://doi.org/10.1007/s13349-018-0268-5.

[19] Ceravolo R, Lenticchia E, Miraglia G. Spectral entropy of acceleration data for damage detection in masonry buildings affected by seismic sequences. Constr Build Mater 2019;210:525-39. https://doi.org/10.1016/j.conbuildmat.2019.03.172.

[20] Ubertini F, Comanducci G, Cavalagli N. Vibration-based structural health monitoring of a historic bell-tower using output-only measurements and multivariate statistical analysis. Struct Heal Monit An Int J 2016;15:438-57. https://doi.org/10.1177/1475921716643948.

[21] Zampieri P, Amoroso M, Pellegrino C. The masonry buttressed arch on spreading support. Structures 2019;20:226-36. https://doi.org/10.1016/j.istruc.2019.03.008. 
[22] Scozzese F, Ragni L, Tubaldi E, Gara F. Modal properties variation and collapse assessment of masonry arch bridges under scour action. Eng Struct 2019;199:109665. https://doi.org/10.1016/j.engstruct.2019.109665.

[23] Magalhães F, Cunha Á. Explaining operational modal analysis with data from an arch bridge. Mech Syst Signal Process 2011;25:1431-50. https://doi.org/10.1016/j.ymssp.2010.08.001.

[24] Gustavsen B, Semlyen A. Rational approximation of frequency domain responses by vector fitting. IEEE Trans Power Deliv 1999;14:1052-9. https://doi.org/10.1109/61.772353.

[25] Grivet-Talocia S, Gustavsen B. Passive Macromodeling: Theory and Applications. Wiley; 2016.

[26] Salawu OS. Detection of structural damage through changes in frequency: a review. Eng Struct 1997;19:718-23. https://doi.org/10.1016/S0141-0296(96)00149-6.

[27] Onat O. Impact of mechanical properties of historical masonry bridges on fundamental vibration frequency. Structures 2020;27:1011-28. https://doi.org/10.1016/j.istruc.2020.07.014.

[28] Schwarz BJ, Richardson MH. Experimental Modal Analysis. 1999.

[29] Grivet-Talocia S. Package Macromodeling via Time-Domain Vector Fitting. IEEE Microw Wirel Components Lett 2003;13:472-4. https://doi.org/10.1109/LMWC.2003.819378.

[30] Grivet-Talocia S. The Time-Domain Vector Fitting Algorithm for Linear Macromodeling. AEÜ Int J Electron Commun 2004;58:1-1. https://doi.org/10.1078/1434-8411-54100245.

[31] Maia NMM, Montalvão e Silva JM (Júlio M. Theoretical and experimental modal analysis. Research Studies Press; 1997.

[32] Gustavsen B. Improving the pole relocating properties of vector fitting. IEEE Trans Power Deliv 2006;21:1587-92. https://doi.org/10.1109/TPWRD.2005.860281.

[33] Deschrijver D, Mrozowski M, Dhaene T, De Zutter D. Macromodeling of multiport systems using a fast implementation of the vector fitting method. IEEE Microw Wirel Components Lett 2008;18:383-5. https://doi.org/10.1109/LMWC.2008.922585.

[34] Figueiredo E, Park G, Figueiras J. Structural Health Monitoring Algorithm Comparisons Using Standard Data Sets. n.d.

[35] Levy EC. Complex-curve fitting. IRE Trans Autom Control 2013;AC-4:37-43. https://doi.org/10.1109/tac.1959.6429401.

[36] Francis JGF. The QR Transformation A Unitary Analogue to the LR Transformation-Part 
1. Comput J 1961;4:265-71. https://doi.org/10.1093/comjnl/4.3.265.

[37] Juang JN, Pappa RS. An eigensystem realization algorithm for modal parameter identification and model reduction. J Guid Control Dyn 1985;8:620-7. https://doi.org/10.2514/3.20031.

[38] Ceravolo R, Abbiati G. Time domain identification of structures: Comparative analysis of output-only methods. J Eng Mech 2013;139:537-44. https://doi.org/10.1061/(ASCE)EM.1943-7889.0000503.

[39] Allemang RJ. The Modal Assurance Criterion (MAC): Twenty Years of Use and Abuse. n.d.

[40] Civera M, Zanotti Fragonara L, Surace C. An experimental study of the feasibility of phasebased video magnification for damage detection and localisation in operational deflection shapes. Strain 2020;56. https://doi.org/10.1111/str.12336.

[41] Ruocci G, Degiovanni L, Quattrone A, Fragonara LZ, Ceravolo R, De Stefano A. Experimental testing of a masonry arch bridge model subject to increasing level of damage. European Commission; 2011.

[42] Ruocci G, Quattrone A, Stefano A De. Multi-domain feature selection aimed at the damage detection of historical bridges. J. Phys. Conf. Ser., vol. 305, Institute of Physics Publishing; 2011. https://doi.org/10.1088/1742-6596/305/1/012106.

[43] Ruocci G. Application of the SHM Methodologies to the Protection of Masonry Arch Bridges from Scour. 2010.

[44] Zampieri P, Zanini MA, Faleschini F, Hofer L, Pellegrino C. Failure analysis of masonry arch bridges subject to local pier scour. Eng Fail Anal 2017;79:371-84. https://doi.org/10.1016/j.engfailanal.2017.05.028.

[45] Kay SM. Modern spectral estimation: theory and application. Pearson Education; 1988.

[46] Worden K, Tomlinson GR. Nonlinearity in structural dynamics : detection, identification, and modelling. Institute of Physics; 2001.

[47] Van Der Auweraer H, Peeters B. Discriminating physical poles from mathematical poles in high order systems: Use and automation of the stabilization diagram. Conf. Rec. - IEEE Instrum. Meas. Technol. Conf., vol. 3, 2004, p. 2193-8. https://doi.org/10.1109/IMTC.2004.1351525.

[48] Peeters B, Van der Auweraer H, Guillaume P, Leuridan J. The PolyMAX FrequencyDomain Method: A New Standard for Modal Parameter Estimation? Shock Vib 
2004;11:395-409. https://doi.org/10.1155/2004/523692.

[49] Curadelli RO, Riera JD, Ambrosini D, Amani MG. Damage detection by means of structural damping identification. Eng Struct 2008;30:3497-504.

https://doi.org/10.1016/j.engstruct.2008.05.024.

[50] Reynders E, Pintelon R, De Roeck G. Uncertainty bounds on modal parameters obtained from stochastic subspace identification. Mech Syst Signal Process 2008;22:948-69. https://doi.org/10.1016/j.ymssp.2007.10.009.

[51] Manos GC, Kourtides V, Sextos A, Renault P, Chiras S. Study of the Dynamic SoilStructure Interaction of a Bridge Pier Model Based on Structures and Soil Measurements. 9th Can. Conf. Earthq. Eng., 2007.

[52] Moughty JJ, Casas JR. A State of the Art Review of Modal-Based Damage Detection in Bridges: Development, Challenges, and Solutions. Appl Sci 2017;7:510. https://doi.org/10.3390/app7050510. 


\section{Appendix A.}

\begin{tabular}{|c|c|c|c|c|c|}
\hline $\begin{array}{c}\text { Hammer } \\
\text { Acquisition }\end{array}$ & $\begin{array}{l}\text { Impact } \\
\text { Point } \\
\text { (Setup) }\end{array}$ & Direction & $\begin{array}{c}\text { Hammer } \\
\text { Acquisition }\end{array}$ & $\begin{array}{c}\text { Impact } \\
\text { Point } \\
\text { (Setup) }\end{array}$ & Direction \\
\hline \#1 & $02 \mathrm{~A}(2)$ & orthogonal to the arch & \#15 & 08A (2) & orthogonal to the arch \\
\hline$\# 2$ & 02B (2) & orthogonal to the arch & \#16 & 08B (2) & orthogonal to the arch \\
\hline$\# \mathbf{3}$ & $02 \mathrm{C}(1)$ & orthogonal to the arch & $\# 17$ & 08C (1) & orthogonal to the arch \\
\hline \#4 & $02 \mathrm{D}(1)$ & orthogonal to the arch & \#18 & 08D (1) & orthogonal to the arch \\
\hline \#5 & 04A (1) & orthogonal to the arch & \#19 & $10 \mathrm{~A}(1)$ & orthogonal to the arch \\
\hline \#6 & 04B (1) & orthogonal to the arch & $\# 20$ & 10B (1) & orthogonal to the arch \\
\hline \#7 & $04 \mathrm{C}(2)$ & orthogonal to the arch & \#21 & $10 \mathrm{C}(2)$ & orthogonal to the arch \\
\hline \#8 & 04D (2) & orthogonal to the arch & $\# 22$ & 10D (2) & orthogonal to the arch \\
\hline \#9 & 06A $(1,2)$ & orthogonal to the arch & $\# 23$ & $12 \mathrm{~A} \mathrm{(2)}$ & longitudinal \\
\hline$\# 10$ & 06B (1.2) & orthogonal to the arch & $\# 24$ & $13 \mathrm{~A}(2)$ & transversal \\
\hline \#11 & $06 \mathrm{C}(1,2)$ & orthogonal to the arch & \#25 & $14 \mathrm{~A}(1,2)$ & transversal \\
\hline \#12 & $06 \mathrm{D}(1,2)$ & orthogonal to the arch & $\# 26$ & $14 \mathrm{C}(1,2)$ & transversal \\
\hline$\# 13$ & 06M (1) & orthogonal to the arch & $\# 27$ & $15 \mathrm{~A}(1,2)$ & vertical \\
\hline \#14 & $06 \mathrm{~N}(1)$ & orthogonal to the arch & \#28 & $15 \mathrm{~B}(1,2)$ & vertical \\
\hline
\end{tabular}

Table A.1. Hammer impact details for Damage Steps \#5-\#8 as utilised for system identification. Impact points as represented in Figure A.1. The same hammer tip was utilised for all tests; every recording lasted 60 seconds (sampling frequency: $400 \mathrm{~Hz}$ ).

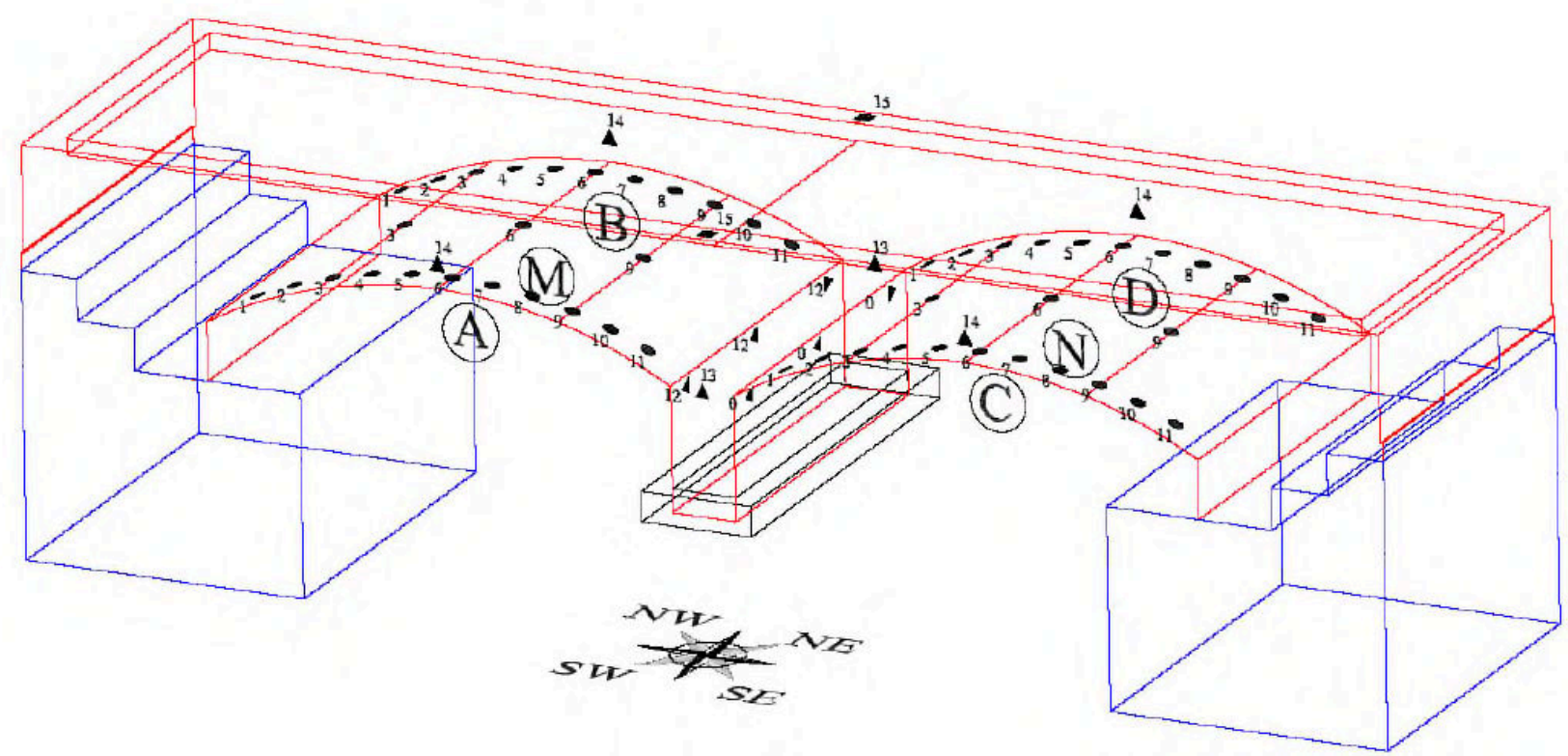

Figure A.1. Locations of the impact points with the corresponding alphanumeric identifier (retrieved from [42]). 
2021-01-23

System identification via fast relaxed vector fitting for the structural health monitoring of masonry bridges

Civera, Marco

Elsevier

Civera M, Calamai G, Zanotti Fragonara L. (2021) System identification via fast relaxed vector fitting for the structural health monitoring of masonry bridges. Structures, Volume 30, April 2021, pp. 277-293

https://doi.org/10.1016/j.istruc.2020.12.073

Downloaded from Cranfield Library Services E-Repository 